\title{
Impact of the Atlantic Meridional Mode on Gulf Stream North Wall Position ${ }^{\mathscr{O}}$
}

\author{
Sultan Hameed, Christopher L. P. Wolfe, AND LeQuan Chi \\ School of Marine and Atmospheric Sciences, Stony Brook University, State University of New York, Stony Brook, New York
}

(Manuscript received 25 February 2018, in final form 15 August 2018)

\begin{abstract}
The path of the Gulf Stream as it leaves the continental shelf near Cape Hatteras is marked by a sharp gradient in ocean temperature known as the North Wall. Previous work in the literature has considered processes related to the North Atlantic Oscillation (NAO) in triggering latitudinal displacements of the North Wall position. This paper presents evidence that the Atlantic meridional mode (AMM) also impacts interannual variations of the North Wall position. The AMM signal from the tropics propagates to the Gulf Stream near the 200-m depth, and there are two time scales for this interaction. Anomalous Ekman suction induced by AMM cools the tropical Atlantic. The cold water in the Caribbean Sea is entrained into the currents feeding the Gulf Stream, and this cooling signal reaches the North Wall within a year. A second mechanism involves cold anomalies in the western tropical Atlantic, which initially propagate westward as baroclinic planetary waves, reaching the Gulf Stream and resulting in a southward shift in the North Wall position after a delay of about one year. In an analysis for the period 1961-2015, AMM's signal dominates North Wall fluctuations in the upper $300 \mathrm{~m}$, while NAO is the major influence below $\sim 500 \mathrm{~m}$; the influence of both the teleconnections is seen between 300 and $500 \mathrm{~m}$. The relationship between the Atlantic meridional overturning circulation (AMOC) and the North Wall is investigated for the 2005-15 period and found to be statistically significant only at the sea surface in one of the three North Wall indices used.
\end{abstract}

\section{Introduction}

The Gulf Stream flows nearly parallel to the American coast until Cape Hatteras, where it turns northeastward flowing as a free jet. The northern edge of the current is marked by a sharp temperature front that separates the waters of the Gulf Stream from the waters of the continental shelf and slope sea to the north. This front persists to great depth and has the appearance of a wall in temperature sections; this front is thus often referred to as the Gulf Stream North Wall. While the point where the Gulf Stream diverges from the coast is remarkably stable (Chassignet and Marshall 2008), east of Cape Hatteras the latitude of the North Wall varies on time scales ranging from intraseasonal to decadal and longer (e.g., Taylor and Stephens 1980; Joyce et al. 2000; Rossby et al. 2010; Lillibridge and Mariano 2013).

Supplemental information related to this paper is available at the Journals Online website: https://doi.org/10.1175/JCLID-18-0098.s1.

Corresponding author: Sultan Hameed, sultan.hameed@ stonybrook.edu
Fluctuations in the North Wall position can have consequences for regional weather. Rapidly deepening bomb cyclones tend to move along the axis of the Gulf Stream (Sanders 1986), and it is marked by enhanced synoptic variability of surface winds, vertical vorticity, and latent heat loss (Joyce et al. 2009). Shifts in the position of the North Wall are important also for marine biology, as it separates the cold, biologically productive slope water to the north from the warm, less productive Sargasso Sea to the south. Impact of North Wall position on plankton populations in New England coastal waters has been documented by Borkman and Smayda (2009) and on fish stocks in the same region by Nye et al. (2011) and $\mathrm{Xu}$ et al. (2018). Through its impact on atmospheric circulation, the position of the North Wall also affects marine biological cycles in the lakes and coastal waters of Europe (Taylor 1995; Planque and Taylor 1998; Jennings and Allott 2006).

Several investigators have suggested that the North Atlantic Oscillation (NAO) exercises control on the North Wall's position (Pickart et al. 1997; Taylor and Stephens 1998; Joyce et al. 2000; Hameed and Piontkovski 2004; Zhang and Vallis 2006). There is evidence that when the NAO is in a low state and winter conditions in the 
North Atlantic are milder, Labrador Sea Water flows preferentially westward toward the shelf into the slope sea from the Grand Banks. However, when the NAO is in a high state in anomalously cold winters, the colder waters sink in the Labrador Sea and the subducted water moves primarily eastward. This results in a decrease of westward transport around the Grand Banks, generating warmer temperatures on the shelf and a northward shift of the North Wall (Rossby 1999). However, a definitive explanation of how a signal from the NAO influences the North Wall position has yet to be developed.

A range of time lags between the NAO and the North Wall have been reported by different authors using different definitions of the North Wall and different time intervals for the calculations. For example, Rossby and Benway (2000) estimated a lag of 1.5 years between the NAO and salinity anomalies in the slope sea using observations in the period 1978-98. Taylor and Stephens (1998), using data for 1966-96, found that the correlation between the NAO and their North Wall index is statistically significant at a 2-yr lag but not at zero lag. In contrast, Sanchez-Franks et al. (2016) report that the North Wall index of Taylor and Stephens during 19662014 has statistically significant correlations with lags of zero, 1 , and 2 years. This illustrates that the correlation is not statistically stationary but can change with time. Joyce et al. (2000) found that the correlation between their North Wall index and the NAO during 1955-89 is statistically significant at lags of zero and 1 year; however, when the time span was extended to 1955-98 and a different definition of the NAO was used, the correlation was found to be statistically significant at a 1-yr lag (Frankignoul et al. 2001). Pérez-Hernández and Joyce (2014) devised an index of Gulf Stream position based on sea level anomalies for 1992-2012 and found that it was correlated with the NAO at a lag of 1 year. Watelet et al. (2017) report a statistically significant correlation with a lag of 1 year during 1940-2014; however, we find the correlation to be statistically significant only at zero lag when using a DJF NAO index, as reported in section 5 of this paper.

This paper investigates the imprint of the NAO on the North Wall with depth up to $1000 \mathrm{~m}$ and compares it with the impact of the Atlantic meridional mode (AMM). The AMM is a coupled mode of interannual atmosphere-ocean variability in the tropical Atlantic associated with the meridional migration of the intertropical convergence zone. The AMM has been shown to have a significant impact on rainfall over the tropical Atlantic (Kushnir et al. 2006) and is also linked with hurricane activity in the North Atlantic (Vimont and Kossin 2007; Patricola et al. 2014). Relationships between anomalies of winds, evaporation, and SST in the evolution of AMM in observations and also in CMIP5 models are discussed by Amaya et al. (2017). It is found that the AMM signal reaches the North Wall more quickly than the NAO's signal. An advective transport process carries the AMM signal in the tropical Atlantic to the North Wall within a year, and another mechanism initially mediated by planetary waves takes about one year to reach the North Wall.

The Gulf Stream is a part of the upper-level flow in the Atlantic meridional overturning circulation (AMOC). Direct observations of AMOC are available only since April 2004. Using a proxy for AMOC to extend the length of its time series, Joyce and Zhang (2010) and Sanchez-Franks and Zhang (2015) concluded that the variability of the Gulf Stream path is related to the strength of the AMOC. Other recent studies suggest that the large AMOC decline in 2009/10 caused a concurrent Gulf Stream path shift (Pérez-Hernández and Joyce 2014; Ezer 2015; Goddard et al. 2015; Zeng and He 2016). In the present paper, relationships between AMOC and North Wall indices are investigated using available AMOC observation estimates. The results show that the impact of AMOC on the North Wall is found in only one of the North Wall indices.

Several approaches to define the latitude of the North Wall have been presented in the literature, such as the location of the $15^{\circ} \mathrm{C}^{1}$ isotherm at $200 \mathrm{~m}$ (Fuglister 1955; Cornillon and Watts 1987; Gangopadhyay et al. 1992; Joyce et al. 2000; Frankignoul et al. 2001; Chaudhuri et al. 2011), the $12^{\circ} \mathrm{C}$ isotherm at $400 \mathrm{~m}$ (Bryan et al. 2007; Zhang 2008; Joyce and Zhang 2010), the $17^{\circ} \mathrm{C}$ isotherm at $200 \mathrm{~m}$ (Sasaki and Schneider 2011), and frontal analysis of sea surface temperature (Taylor and Stephens 1980, 1998; Taylor 2005; Drinkwater et al. 1994; Watelet et al. 2017). For any of these measures, an index of North Wall position can be calculated as the first principal component (PC) obtained by empirical orthogonal function (EOF) analysis of the spatial data.

Several indices of the North Wall that are available for multidecadal durations are analyzed in this paper. The index calculated by Joyce et al. (2000) is based on the $15^{\circ} \mathrm{C}$ isotherm at $200 \mathrm{~m}$, and it is available for $1954-2012$. We have extended the index of Joyce et al. (2000) to 2015 and also calculated it at depths from the surface to $1000 \mathrm{~m}$.

Three North Wall indices based on SSTs are analyzed. The index presented by Taylor and Stephens (1998) is calculated from frontal analysis of SST data and is available for 1966-2014. Another index from objective

\footnotetext{
${ }^{1}$ Unless otherwise noted, all subsurface temperatures are potential rather than in situ temperatures.
} 
SST frontal analysis by Watelet et al. (2017) is available for 1940-2014. The North Wall index at the sea surface calculated using the procedure of Joyce et al. (2000) is also analyzed. Table 1 lists the North Wall indices discussed in this paper.

Section 2 describes the North Wall indices and the AMM indices. Interactions of AMM and NAO with the North Wall at the 200-m depth are discussed in section 3. Section 4 describes these interactions at the sea surface, where it is noted that different index formulations yield different correlations with NAO and AMM. Reasons for the differences are discussed in section 5. Section 6 focuses on how the AMM impacts the North Wall between 200- and 1000-m depths. Possible relationships between the North Wall, AMOC, NAO, and AMM are presented in section 7. The main conclusions are summarized in section 8 .

\section{Data and methods}

The Gulf Stream North Wall (GSNW) index of Taylor and Stephens $(1980,1998)$ is based on surface frontal analyses provided by the U.S. Naval Oceanographic Office and the National Oceanic and Atmospheric Administration. In this product, the location of the North Wall is determined subjectively using in situ measurements of SST as well as by aircraft and satellite remote sensing. The GSNW index is then given by the principal component of the first EOF of the North Wall latitude at six selected longitudes. The GSNW index is currently available for 1966-2014.

In an effort to overcome subjectivity in the procedure of Taylor and Stephens (1980), Watelet et al. (2017) determine the location of the maximum SST gradient by fitting the error function to monthly SSTs at 81 equally spaced zonal positions between $70^{\circ}$ and $50^{\circ} \mathrm{W}$. The 81 fits were then filtered by assigning weights proportional to their goodness of fit. The North Wall index was derived by calculating the first principal component of the 81 latitudes for each month and then averaging them to produce an annual index. This index is referred to as wGSNW in this paper, and its annual values are available for 1940-2014.

The index developed by Joyce et al. (2000) is called the Gulf Stream index (GSI) in this paper. It is constructed using the 200-m temperature at nine locations between $75^{\circ}$ and $55^{\circ} \mathrm{W}$. These locations lie on the mean position of the $15^{\circ} \mathrm{C}$ isotherm, which itself lies near the center of the strong horizontal temperature gradient of the Gulf Stream just to the north of the maximum flow at the surface. Joyce et al. (2000) chose the 200-m depth because it is below the seasonal mixed layer, so the flow is not directly affected by diabatic processes, and fewer
TABLE 1. List of indices for the Gulf Stream North Wall latitude analyzed in this paper.

\begin{tabular}{lcc}
\hline \hline Index & \multicolumn{1}{c}{ Description } & Reference \\
\hline GSI & $\begin{array}{c}\text { PC1 of 200-m temperature at } \\
\text { nine fixed points between } 75^{\circ}\end{array}$ & Joyce et al. (2000) \\
& and $55^{\circ} \mathrm{W}$. & \\
eGSI & $\begin{array}{c}\text { Same as GSI calculated at } \\
\text { different layers from surface }\end{array}$ & This study \\
& to $1000 \mathrm{~m}$. & \\
GSNW & PC1 of SST front latitude at & Taylor and Stephens \\
& longitudes $79^{\circ}, 75^{\circ}, 72^{\circ}, 70^{\circ}$, & (1980, 1998) \\
& $67^{\circ}$, and $65^{\circ} \mathrm{W}$ using & \\
& subjective frontal analysis. & \\
wGSNW & PC1 of SST front latitude at 81 & Watelet et al. (2017) \\
& longitudes between $70^{\circ}$ and & \\
& $50^{\circ} \mathrm{W}$ using objective frontal & \\
& analysis. \\
\hline
\end{tabular}

data were available at greater depths. The GSI is the principal component of the first EOF of 200-m temperature at these locations. Since temperature perturbations at the nine locations are proportional to the north-south displacements of the $15^{\circ} \mathrm{C}$ isotherm, changes in the GSI are taken to represent North Wall movement at the 200-m depth. The loading pattern of the first EOF is single signed and thus represents a coherent north-south shift of the Gulf Stream North Wall.

We have followed the procedure given by Joyce et al. (2009) and updated the GSI time series to 2015 using the World Ocean Database (WOD) archive, the same dataset used by Joyce et al. (2009). The temperature profiles in WOD are sparse in the Gulf Stream region prior to 1961, so analyses reported in this paper use the interval 1961-2015, except those with AMOC transport, which are for 2005-15.

To extend the investigation to depths other than $200 \mathrm{~m}$, we calculate an extended GSI (eGSI) over the depth range $1000 \mathrm{~m}$ to the surface using the procedure of Joyce et al. (2009) with the following exceptions: (i) the westernmost point $\left(35.67^{\circ} \mathrm{N}, 75^{\circ} \mathrm{W}\right)$ used by Joyce et al. $(2000,2009)$ is not included because the water depth there is less than $200 \mathrm{~m}$, and (ii) the eGSI is derived from EN4 (Good et al. 2013) data because its interpolation scheme is more sophisticated, and it draws from a broader set of observations. At each (standard) depth, the eGSI is the PC of the leading EOF of temperature at the eight selected locations. The loading patterns of the EOFs are single signed at every depth considered and so represent a coherent north-south shift of the temperature distribution. The eGSI obtained at $200 \mathrm{~m}$ (eGSI200) is compared with the GSI in Fig. 1a for the period 1961-2015. Their mutual correlation for this period is 0.83 . Values of eGSI at nine depth levels are given in the online supplemental material of this paper. 

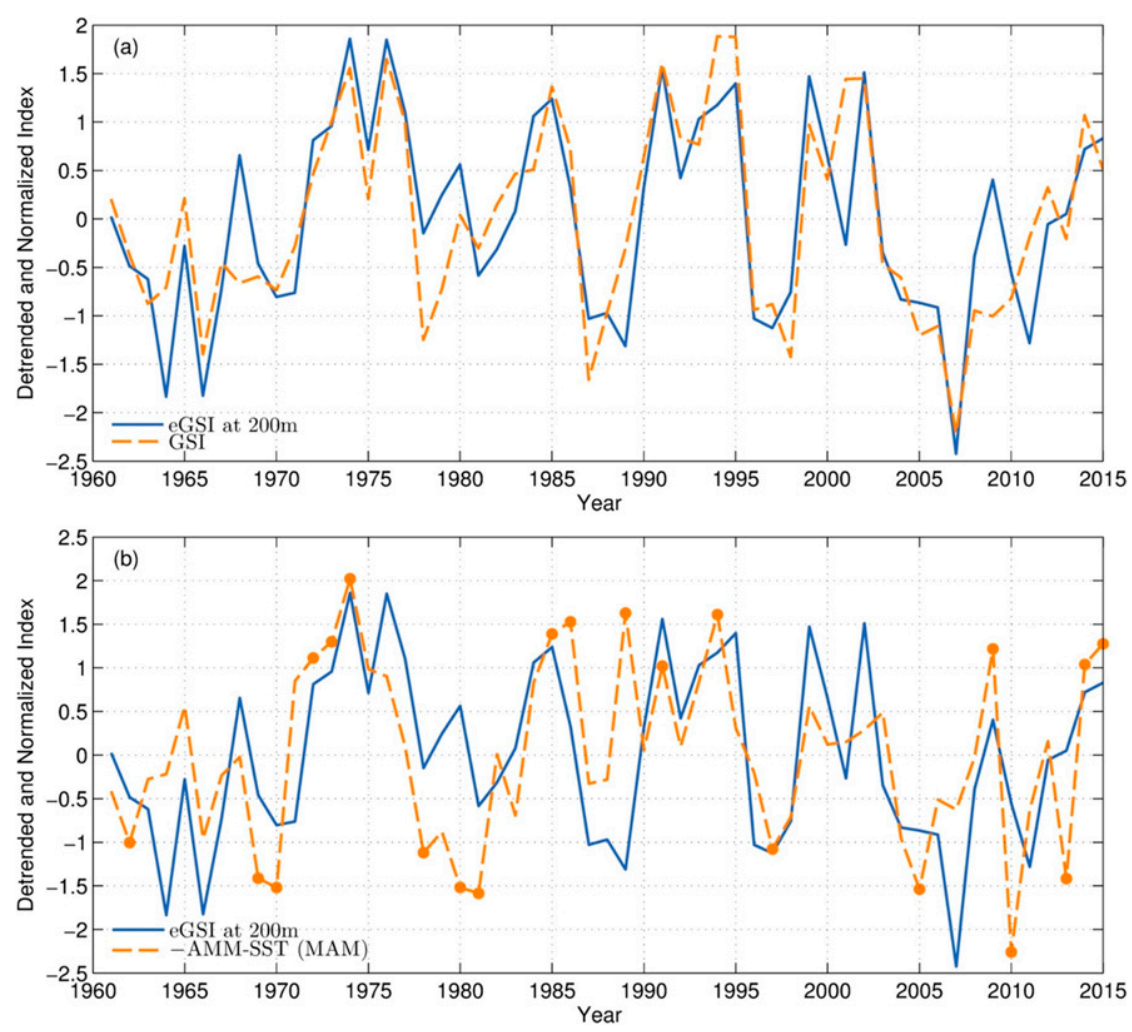

FIG. 1. (a) Comparison of eGSI-200 and GSI North Wall indices at $200 \mathrm{~m}$ during 1961-2015. (b) Time series of the eGSI-200 at the 200-m depth and AMM SST index. The high- and lowAMM years used for the composite analysis are indicated by filled circles. The sign of the AMM index has been reversed.

The WOD is a collection of worldwide in situ observations with quality controls provided by National Centers for Environmental Information (formerly the National Oceanographic Data Center) of National Oceanic and Atmospheric Administration (NOAA). While a stable version of WOD is published every few years (e.g., WOD 96, WOD 01) an up-to-date version of WOD is also provided with newly added records after the last stable version. Besides the observational layers, WOD also provides data at standard vertical levels. The most recent WOD stable version (WOD 2013) contains 138 standard levels (Boyer et al. 2013).

The EN4 dataset is a $1^{\circ} \times 1^{\circ}$ gridded temperature and salinity dataset with 42 vertical layers. It is derived from optimal interpolation of multiple sources of in situ profiles, including WOD and the Global Temperature and Salinity Profile Program (GTSPP). EN4 is published by Met Office Hadley Centre, United Kingdom, and covers the period of 1900 to present (Good et al. 2013).

By regressing the eGSI-200 against EN4 200-m temperature data, we find that eGSI-200 values of \pm 1 correspond to a nearly zonally uniform north or south shift of $0.25^{\circ}$. Since the total range of the eGSI- 200 is approximately
4, the maximum excursion of the North Wall as represented by the eGSI-200 is about $1^{\circ}$. These values are consistent with those found by Ezer (1999).

Indices representing the AMM have been calculated by Chiang and Vimont (2004) using maximum covariance analysis of SST and wind. The time variation is given by the first principal component time series of each of these variables. Monthly values of SST and wind time series are available for 1948 to the present from Vimont (2015). The wind and SST time series are highly correlated with each other, with the SST time series lagging the wind time series by about a month. The wind time series represents both the coupled oscillation and its forcing, while the SST time series is primarily representative of the oscillation itself (Chiang and Vimont 2004); we therefore consider the SST time series only. The annual variation of the AMM SST time series has its highest amplitudes in March, April, and May (MAM; Chiang and Vimont 2004); thus, its average over the MAM season is used in this work to represent AMM.

DJF averages of the NAO index calculated by NOAA's Climate Prediction Center as the first principal component obtained by rotated principal component 
TABLE 2. Correlations of eGSI-200 with NAO and AMM during 1961-2015. Correlations with subscripts are partial correlations where the subscripted index is held fixed. Statistical tests for which $p<0.05$ are taken as significant and are shown in bold.

\begin{tabular}{|c|c|c|c|c|c|}
\hline Correlation & Lag 0 & Lag 1 & Lag 2 & Lag 3 & Lag 4 \\
\hline$r(\mathrm{NAO}, \mathrm{eGSI}-200)$ & 0.38 & 0.36 & 0.30 & 0.07 & 0.00 \\
\hline$r(\mathrm{AMM}, \mathrm{eGSI}-200)$ & -0.56 & -0.41 & -0.18 & -0.05 & 0.10 \\
\hline$r(\mathrm{NAO}, \mathrm{eGSI}-200)_{\mathrm{AMM}}$ & 0.18 & 0.22 & 0.25 & 0.06 & 0.04 \\
\hline$r(\mathrm{AMM}, \mathrm{eGSI}-200)_{\mathrm{NAO}}$ & -0.47 & -0.31 & -0.06 & -0.02 & 0.11 \\
\hline
\end{tabular}

analysis of 500-m geopotential height anomalies are used in this paper.

Observations of all the components that contribute to AMOC are available from the RAPID-AMOC project since April 2004 (McCarthy et al. 2015). Thus, an annually averaged AMOC index is available for 2005-present. The short annual time series does not reveal statistically significant correlations with the North Wall, AMM, or NAO. To increase the sample size, averages for the seasons January-March (JFM), April-June (AMJ), July-September (JAS), and OctoberDecember (OND) were calculated for AMOC, AMM, NAO, and GSI.

In calculations not involving AMOC, annually averaged values of North Wall indices were used. Data used in the calculations were detrended by subtracting a linear fit. The effective number of independent variables needed to test statistical significance of correlations was estimated by the method of Quenouille (1952),

$$
\frac{1}{n_{\mathrm{eff}}}=\frac{1}{n}\left(1+2 \sum_{i=1}^{\infty} r_{i} r_{i}^{\prime}\right)
$$

where $n$ is the number of data points in each time series and $r_{i}$ and $r_{i}^{\prime}$ are the lag- $i$ autocorrelations of the two series. In practice, the autocorrelation with infinite lag cannot be reached. Thus, the sum is truncated when $2 r r^{\prime} \leq R_{\text {cut }}$ or at 10 terms, whichever occurs first. The cutoff value,

$$
R_{\text {cut }}=\frac{2}{n-1}
$$

is twice the square of the standard error of the lag- 1 autocorrelation of a white noise time series of length $n$. The maximum number of terms (10) is set considering that the North Wall variations are mainly at periods no more than 10 years (Gangopadhyay et al. 2016) and enough length of times series is required to get reliable correlation coefficients. Statistical tests for which $p<$ 0.05 are taken as significant and are shown in bold in Tables 2-11.
TABLE 3. As in Table 2, but for correlations of eGSI-0 with AMM

\begin{tabular}{|c|c|c|c|c|c|}
\hline Correlation & Lag 0 & Lag 1 & Lag 2 & Lag 3 & Lag 4 \\
\hline$r(\mathrm{NAO}, \mathrm{eGSI}-0)$ & 0.54 & 0.29 & 0.04 & 0.01 & -0.11 \\
\hline$r(\mathrm{AMM}, \mathrm{eGSI}-0)$ & -0.55 & -0.40 & -0.11 & -0.06 & 0.11 \\
\hline$r(\mathrm{NAO}, \mathrm{eGSI}-0)_{\mathrm{AMM}}$ & 0.40 & 0.14 & 0.00 & -0.01 & -0.07 \\
\hline$r(\mathrm{AMM}, \mathrm{eGSI}-0)_{\mathrm{NAO}}$ & -0.41 & -0.32 & 0.10 & -0.06 & 0.07 \\
\hline
\end{tabular}
and NAO at lags up to 4 years during 1961-2015.

\section{Relationship between the North Wall, AMM, and NAO at the 200-m depth}

As described in section 2, the GSI was calculated by Joyce et al. (2000) at the 200-m depth, and we have used their procedure to calculate the eGSI for all standard depths from the surface to $1000 \mathrm{~m}$. We first discuss the relationship of eGSI-200 with AMM, because it leads to understanding its interactions at the sea surface (section 4) and at depths below $200 \mathrm{~m}$ (section 6).

\section{a. Correlations of eGSI-200 with AMM and NAO}

Correlations calculated with lags up to 4 years are shown in Table 2. As seen in row 1 of the table, the correlations with NAO are statistically significant for lags of zero and 1 years, with NAO leading eGSI-200, which is consistent with the correlations between NAO and GSI reported by Joyce et al. (2000). The correlations of AMM with eGSI-200 shown in row 2 are negative and statistically significant for lags of zero and 1 years. However, the AMM's correlation at lag zero $(-0.56)$ is stronger than that of NAO $(0.38)$.

Both AMM and NAO have statistically significant correlations with eGSI-200 at lags of zero and 1 years. However, the NAO and AMM are not independent of each other: their mutual correlation of -0.44 is statistically significant. Thus, the correlation coefficients reflect both direct contributions of NAO and AMM to eGSI200 as well as indirect contributions from the mutual correlation between NAO and AMM. To isolate the effects of each of the forcing variables, we computed partial correlation coefficients (see, e.g., Hamby 1994), shown in the last two rows of Table 1 . In the third row, we see that the correlation between NAO and GSI becomes insignificant when controlled for AMM. On the

TABLE 4. As in Table 2, but for correlations of GSNW with AMM

\begin{tabular}{|c|c|c|c|c|c|}
\hline Correlation & Lag 0 & Lag 1 & Lag 2 & Lag 3 & Lag 4 \\
\hline$r(\mathrm{NAO}, \mathrm{GSNW})$ & 0.41 & 0.52 & 0.40 & 0.15 & -0.02 \\
\hline$r(\mathrm{AMM}, \mathrm{GSNW})$ & -0.28 & -0.37 & -0.05 & -0.13 & -0.01 \\
\hline$r(\mathrm{NAO}, \mathrm{GSNW})_{\mathrm{AMM}}$ & 0.32 & 0.42 & 0.42 & 0.10 & -0.02 \\
\hline$r(\mathrm{AMM}, \mathrm{GSNW})_{\mathrm{NAO}}$ & -0.12 & -0.18 & 0.15 & -0.07 & -0.02 \\
\hline
\end{tabular}
and NAO during 1966-2014 at lags up to 4 years. 
TABLE 5. As in Table 2, but for correlations of wGSNW with AMM and NAO during 1961-2014 at lags up to 4 years.

\begin{tabular}{|c|c|c|c|c|c|}
\hline Correlation & Lag 0 & Lag 1 & Lag 2 & Lag 3 & Lag 4 \\
\hline$r(\mathrm{NAO}, \mathrm{wGSNW})$ & 0.51 & 0.18 & -0.10 & -0.21 & -0.23 \\
\hline$r(\mathrm{AMM}, \mathrm{wGSNW})$ & -0.31 & -0.06 & 0.19 & 0.10 & 0.02 \\
\hline$r(\mathrm{NAO}, \mathrm{wGSNW})_{\mathrm{AMM}}$ & 0.44 & 0.18 & -0.03 & -0.18 & -0.25 \\
\hline$r(\mathrm{AMM}, \mathrm{wGSNW})_{\mathrm{NAO}}$ & -0.12 & 0.02 & 0.16 & 0.02 & -0.09 \\
\hline
\end{tabular}

other hand, the correlation between AMM and eGSI200 remains statistically significant at zero- and 1-yr lags when controlled for NAO.

These results suggest that the primary influence on eGSI-200 in a given year is from AMM in the concurrent year (zero lag) and a weaker signal from the prior year. The eGSI-200 and AMM time series are shown (without lag) in Fig. 1b, where similarity between their variations can be seen.

To explore possible physical relationships for these correlations, we made composites of 200-m temperature for high- and low-AMM states using the AMM SST series. "High" and "low" years are defined as those in which the value of the AMM index is greater than or less than, respectively, its mean by one standard deviation. The AMM high and low years are marked in Fig. 1b. The differences in $200-\mathrm{m}$ temperatures between composites (i.e., the averages) of high- and lowAMM years are shown in Fig. 2a when AMM index and temperatures are simultaneous (i.e., no time lag between them), and Fig. $2 b$ shows the differences when the AMM leads temperatures by one year. Contours show areas where the temperature differences are statistically significant. The nine locations whose temperatures are used in calculating the GSI are also shown in Figs. 2a and 2b.

In Fig. 2a, an area of statistically significant differences in temperature is seen between $10^{\circ}$ and $20^{\circ} \mathrm{N}$, extending northward through the Caribbean into the North Wall region. The figure shows that high-AMM states induce cooling and low-AMM states cause warming in the tropics at $200 \mathrm{~m}$ and in the Gulf Stream. Composite differences of nearly $1^{\circ} \mathrm{C}$ are seen in the Caribbean and in the Gulf Stream. This composite is for zero lag and thus suggests that perturbations induced by the AMM in the tropics reach the North Wall within the year.

Figure $2 b$ shows that another AMM signal from the tropics reaches the North Wall with a delay of about one year. In comparison with Fig. 2a, there is a region of weak but statistically significant cooling extending eastward from the Gulf Stream around $30^{\circ}$ N. Joyce et al. (2000) observed that when the Gulf Stream shifts south, the 200-m temperatures to the south of it are colder and vice versa, further noting that the thermal signals in the Sargasso Sea cannot be induced by shifts in the Gulf Stream position. Figure $2 \mathrm{~b}$ indicates that the cooling in the Sargasso Sea is related to the AMM, but an explanation for this is outside the scope of this paper.

Composites made for lags of 2 or more years (not shown) do not display statistically significant differences in temperatures between high- and low-AMM states, consistent with the insignificant correlations between AMM and eGSI-200 at these higher lags.

\section{b. Relationship between the AMM and 200-m temperatures in tropical Atlantic}

To further explore the relationships seen in Fig. 2, we performed an EOF decomposition of 200-m temperature in the tropical North Atlantic $\left(10^{\circ}-30^{\circ} \mathrm{N}, 90^{\circ}-20^{\circ} \mathrm{W}\right)$. The first EOF pattern is shown in Fig. 3. It explains $23 \%$ of the variance of $200-\mathrm{m}$ temperature in this region. It has the same sign throughout the region south of $25^{\circ} \mathrm{N}$ except near the eastern boundary. The loading coefficients are highest in the west, especially around the Caribbean, in the same region where strong cooling is found in Fig. 2a. The first principal component has a statistically significant correlation $(-0.45)$ with AMM. We can thus infer that the composite temperature differences in the tropical Atlantic in Fig. 2a with zero lag arise because the AMM is correlated with the dominant pattern of temperature

TABLE 6. Effects of choices made in computing the correlation between NAO and wGSNW. Choices for the NAO data series are from the Hurrell et al. (2003) PC and the PC of CPC. Statistical tests for which $p<0.05$ are taken as significant and shown in bold.

\begin{tabular}{|c|c|c|c|c|c|c|c|}
\hline Duration & NAO & Detrended & Lag 0 & Lag 1 & Lag 2 & Lag 3 & Lag 4 \\
\hline 1940-2014 & Annual-Hurrell, PC & No & 0.18 & 0.37 & 0.00 & 0.14 & -0.07 \\
\hline 1940-2014 & DJF-Hurrell, PC & No & 0.47 & 0.22 & 0.05 & 0.12 & -0.11 \\
\hline 1940-2014 & Annual-Hurrell, PC & Yes & 0.15 & 0.35 & -0.03 & 0.11 & -0.09 \\
\hline 1940-2014 & DJF-Hurrell, PC & Yes & 0.44 & 0.17 & 0.00 & 0.08 & -0.17 \\
\hline 1940-2014 & Annual-CPC & Yes & 0.12 & 0.29 & -0.12 & -0.01 & -0.24 \\
\hline 1940-2014 & $\mathrm{DJF}-\mathrm{CPC}$ & Yes & 0.51 & 0.23 & -0.06 & -0.09 & -0.17 \\
\hline 1961-2014 & Annual-CPC & Yes & 0.24 & 0.30 & -0.08 & -0.02 & $-\mathbf{0 . 3 1}$ \\
\hline 1961-2014 & $\mathrm{DJF}-\mathrm{CPC}$ & Yes & 0.51 & 0.18 & -0.10 & -0.20 & -0.23 \\
\hline
\end{tabular}


TABLE 7. As in Table 2, but for correlations of the annually averaged eGSI-200 with AMM, NAO, and AMOC during 2005-15 at lags up to 4 years.

\begin{tabular}{lrrrrr}
\hline \hline \multicolumn{1}{c}{ Correlation } & Lag 0 & Lag 1 & Lag 2 & Lag 3 & Lag 4 \\
\hline$r($ AMM, eGSI-200) & -0.41 & -0.20 & 0.19 & 0.09 & 0.40 \\
$r$ (NAO, eGSI-200) & 0.28 & 0.47 & -0.08 & 0.02 & -0.07 \\
$r($ AMOC, eGSI-200) & -0.18 & 0.20 & 0.20 & 0.28 & 0.04 \\
\hline
\end{tabular}

variation (the first EOF) at $200 \mathrm{~m}$, which is geographically coherent in this region.

The AMM is a coupled mode of SST and surface winds, and so it affects Ekman pumping in this region. The Ekman pumping velocity is defined as

$$
w_{\mathrm{Ek}}=\operatorname{curl} \frac{\boldsymbol{\tau}}{\rho_{0} f},
$$

where $\boldsymbol{\tau}$ is the surface wind stress obtained from the NCEP-NCAR Reanalysis 1 (Kalnay et al. 1996), $\rho_{0}=1025 \mathrm{~kg} \mathrm{~m}^{-3}$, and $f$ is the Coriolis parameter. Figure 4 shows the differences in Ekman pumping velocity, averaged over MAM and JJA, between the years in which AMM was in a high state and the years in which it was in a low state. Ekman suction anomalies in the Caribbean Sea and western tropical Atlantic are visible in the MAM composite and become more distinct in the JJA composite. Winds are more variable in MAM than in JJA, so the MAM composite is confounded by other modes of atmospheric variability, such as the NAO. Further, the AMM shows significant seasonal persistence (the correlation coefficient between MAM and JJA averages is 0.74 ), so the AMM is usually strong in JJA if it was strong in MAM. The largest values of $w_{\mathrm{Ek}}$ seen in Fig. $4 \mathrm{~b}$ are in close proximity to where strong cooling is seen in Fig. 2a, although with small differences in location that are likely attributable to the use of annual rather than seasonal means in Fig. 2a and the spatial distribution of the data used to construct EN4. Figure 4 supports the view that perturbation of surface winds associated with AMM induces anomalous Ekman suction in the tropical zone that gives rise to the cooling seen in Fig. 2a.

\section{c. Transfer of the AMM signal from the tropical Atlantic to the North Wall}

The cooling signal in the Caribbean region in Fig. 2a can move rapidly in the Gulf Stream. We estimate that northward transport from $20^{\circ}$ to $35^{\circ} \mathrm{N}$ takes about 66 days, based on the 1993-2015 mean Gulf Stream path and 200-m velocities. To make this estimate, we defined the Gulf Stream path as the axis with maximum downstream velocity at the sea surface using the 1993-2015 mean velocity field from satellite altimeters (Global Ocean Gridded L4 Sea Surface Heights and Derived Variables Reprocessed; http://marine.copernicus.eu/). The Gulf Stream path between $20^{\circ}$ and $35^{\circ} \mathrm{N}$ is shown in Fig. 5. The travel time was then estimated using the average velocity field at $200 \mathrm{~m}$ from Armor3D, version 4 (Copernicus Marine Environmental Monitoring Service 2017). The path was divided into 1000 sections, and the 200-m absolute velocity in each section was interpolated from the mean velocity field of Armor3D. The travel time was estimated as the sum of advection times in all sections. For about $6.5 \%$ of the path, the Gulf Stream velocity maximum is located in water shallower than $200 \mathrm{~m}$. For these sections the vertical mean velocity was used.

The eGSI-200 is additionally correlated with the AMM lagged by 1 year, as seen in Fig. $2 \mathrm{~b}$. In the $10^{\circ}-$ $20^{\circ} \mathrm{N}$ zone there are areas of $0.5^{\circ}-1^{\circ} \mathrm{C}$ cooling occurring in a wavelike sequence suggesting westward propagating waves. These are likely planetary waves excited by the anomalous Ekman suction in the western tropical Atlantic. The Rossby wave speed in this latitude band in the Atlantic has been estimated as $6-7 \mathrm{~cm} \mathrm{~s}^{-1}$ (Cipollini et al. 2001), which is approximately double the mean westward velocity at $200 \mathrm{~m}$ in this region. Assuming the signal propagates with the planetary wave speed yields a travel time from $\sim 45^{\circ} \mathrm{W}$ to the eastern edge of the Caribbean Sea $\left(\sim 60^{\circ} \mathrm{W}\right)$ of about 9.5 months.

If the coastline were straight and mean currents absent, the fraction of wave energy not reflected back into the open ocean or dissipated locally would propagate southward along the coast as a coastal-trapped wave

TABLE 8. As in Table 2, but for correlations of the seasonally averaged eGSI-200 with AMM, NAO, and AMOC during 2005-15 at lags up to 6 seasons.

\begin{tabular}{|c|c|c|c|c|c|c|c|}
\hline Correlation & Lag 0 & Lag 1 & Lag 2 & Lag 3 & Lag 4 & Lag 5 & Lag 6 \\
\hline$r(\mathrm{GSI}, \mathrm{AMM})$ & -0.20 & -0.26 & -0.46 & -0.40 & -0.16 & -0.10 & -0.11 \\
\hline$r(\mathrm{GSI}, \mathrm{NAO})$ & -0.09 & 0.05 & 0.25 & 0.19 & 0.30 & 0.15 & -0.12 \\
\hline$r(\mathrm{GSI}, \mathrm{AMOC})$ & -0.16 & -0.06 & -0.04 & 0.04 & 0.13 & 0.10 & 0.04 \\
\hline$r(\mathrm{GSI}, \mathrm{AMM})_{\mathrm{AMOC}, \mathrm{NAO}}$ & -0.22 & -0.25 & 0.39 & -0.35 & -0.08 & -0.07 & -0.18 \\
\hline$r(\mathrm{GSI}, \mathrm{NAO})_{\mathrm{AMOC}, \mathrm{AMM}}$ & -0.07 & -0.02 & -0.23 & -0.08 & -0.24 & 0.09 & -0.23 \\
\hline$r(\mathrm{GSI}, \mathrm{AMOC})_{\mathrm{NAO}, \mathrm{AMM}}$ & -0.10 & -0.07 & -0.20 & -0.02 & -0.04 & -0.03 & 0.18 \\
\hline
\end{tabular}


TABLE 9. As in Table 2, but for correlations of annually averaged eGSI-0 during 2005-15 with AMM, NAO, and AMOC at lags up to 4 years.

\begin{tabular}{lrrrrr}
\hline \multicolumn{1}{c}{ Correlation } & Lag 0 & Lag 1 & Lag 2 & Lag 3 & Lag 4 \\
\hline$r$ (NAO, eGSI) & $\mathbf{0 . 6 9}$ & 0.55 & -0.14 & 0.11 & -0.55 \\
$r(\mathrm{AMM}, \mathrm{eGSI})$ & -0.36 & -0.18 & 0.55 & 0.17 & 0.32 \\
$r(\mathrm{AMOC}, \mathrm{eGSI})$ & 0.40 & 0.53 & 0.37 & -0.14 & -0.28 \\
$r(\mathrm{NAO}, \mathrm{eGSI})_{\text {AMM,AMOC }}$ & 0.53 & 0.35 & 0.01 & 0.39 & -0.38 \\
$r(\mathrm{AMM}, \mathrm{eGSI})_{\text {NAO,AMOC }}$ & 0.04 & 0.00 & 0.45 & 0.39 & -0.03 \\
$r(\mathrm{AMOC}, \mathrm{eGSI})_{\mathrm{NAO}, \mathrm{AMM}}$ & 0.06 & 0.38 & 0.30 & -0.35 & 0.08 \\
\hline
\end{tabular}

(e.g., Godfrey 1975; Liu et al. 1999). The presence of multiple islands and strong mean currents makes the fate of planetary waves impinging on the Caribbean Sea considerably more complex. In the absence of simple theoretical results, we performed a numerical experiment using the realistic global circulation model (GCM) described in the appendix. To assess how signals originating in the tropical Atlantic reach the Gulf Stream, the vertical velocity is perturbed in a manner that mimics the pattern of Ekman suction produced by the AMM (Fig. 4b). Specifically, additional terms were added to tracer equations so that, for example, the temperature equation takes the form

$$
\frac{D \theta}{D t}=\nabla \cdot \mathbf{D}_{\theta}-w_{\mathrm{Ek}} \frac{\partial \theta}{\partial z},
$$

where $\mathbf{D}_{\theta}$ represents any diffusive fluxes of temperature and the additional term is the last term on the rhs; the salinity equation was modified in a similar manner. The salinity response is not explicitly discussed but was included to ensure that the density field responds to the perturbation in a consistent manner. The velocity perturbation is applied only in the tracer equations and so does not affect the momentum or continuity balances. The vertical velocity perturbation $w_{\text {Ek }}$ increases linearly from zero at the bottom $(4300 \mathrm{~m})$ to a maximum of $160 \mathrm{~m} \mathrm{yr}^{-1}$ just below the surface. This linear profile is consistent with the subinertial response of the ocean to Ekman pumping perturbations. The maximum value is 2-4 times greater than that shown in Fig. $4 \mathrm{~b}$ to ensure a detectible response; the observed response is approximately linear, so the response to a weaker event can be estimated simply by scaling the results by the appropriate factor. The spatial footprint of the perturbation is an elongated Gaussian centered at $15^{\circ} \mathrm{N}, 50^{\circ} \mathrm{W}$ shown in Fig. 6a; its temporal envelope is a Gaussian with a half-width at half maximum of 22.25 days centered on 15 July, as shown in Fig. $6 b$.

To distinguish between wave-mediated and advective responses, a temperature-like passive tracer was additionally advected and diffused by the model using insulating boundary conditions at the surface, sides, and bottom. The passive tracer is forced by a source term identical to the temperature perturbation. Explicitly, the temperature-like passive tracer $C_{\theta}$ evolves according to

$$
\frac{D C_{\theta}}{D t}=\nabla \cdot \mathbf{D}_{C_{\theta}}-w_{\mathrm{Ek}} \frac{\partial \theta}{\partial z},
$$

so the passive tracer responds to the temperature perturbation but does not affect any other thermodynamic or dynamic equations. Outside the forcing region, the passive tracer can only be advected and diffused in contrast to temperature anomalies that can also propagate as waves.

The experiment was repeated six times using years separated by seven years. (As a reasonably large prime number, seven years is unlikely to coincide with the period of any internal interannual variability.) For each experiment, a "twin" simulation was run that did not include a vertical velocity perturbation but was otherwise identical. Temperature anomalies are defined by the difference between the perturbed simulation and its unperturbed twin. The results shown in Fig. 7 are an ensemble mean over the six experiments.

The initial response to the imposed Ekman suction is a cooling of approximately $1^{\circ} \mathrm{C}$ in the forcing region (Fig. 7a). Comparison of the temperature and passive tracer fields shows that, in addition to westward advection by the mean flow, the perturbation excites waves that propagate westward faster than the mean flow. The waves impinging upon the coast of South America propagate southeastward, then along the equator

\begin{tabular}{|c|c|c|c|c|c|}
\hline Correlation & Lag 0 & Lag 1 & Lag 2 & Lag 3 & $\operatorname{Lag} 4$ \\
\hline$r(\mathrm{NAO}, \mathrm{GSNW})$ & 0.58 & 0.41 & -0.05 & -0.44 & -0.28 \\
\hline$r(\mathrm{AMM}, \mathrm{GSNW})$ & -0.39 & -0.04 & 0.83 & -0.19 & 0.23 \\
\hline$r(\mathrm{AMOC}, \mathrm{GSNW})$ & 0.06 & 0.78 & 0.18 & -0.40 & -0.28 \\
\hline$r(\mathrm{NAO}, \mathrm{GSNW})_{\mathrm{AMM}, \mathrm{AMOC}}$ & 0.49 & 0.03 & 0.88 & -0.57 & 0.13 \\
\hline$r(\mathrm{AMM}, \mathrm{GSNW})_{\mathrm{NAO}, \mathrm{AMOC}}$ & -0.03 & -0.35 & 0.96 & -0.53 & 0.28 \\
\hline$r(\mathrm{AMOC}, \mathrm{GSNW})_{\mathrm{NAO}, \mathrm{AMM}}$ & -0.17 & 0.78 & -0.63 & 0.12 & -0.24 \\
\hline
\end{tabular}

TABLE 10. As in Table 2, but for correlations of GSNW during 2005-14 with NAO, AMM, and AMOC at lags up to 4 years. 
TABLE 11. As in Table 2, but for correlations of wGSNW with NAO, AMM, and AMOC during 2005-14 at lags up to 4 years.

\begin{tabular}{|c|c|c|c|c|c|}
\hline Correlation & Lag 0 & $\operatorname{Lag} 1$ & Lag 2 & Lag 3 & $\operatorname{Lag} 4$ \\
\hline$r(\mathrm{NAO}, \mathrm{wGSNW})$ & 0.62 & 0.41 & -0.18 & 0.73 & -0.31 \\
\hline$r(\mathrm{AMM}, \mathrm{wGSNW})$ & 0.04 & -0.18 & 0.83 & 0.02 & -0.07 \\
\hline$r(\mathrm{AMOC}, \mathrm{wGSNW})$ & 0.17 & 0.54 & 0.18 & -0.61 & -0.52 \\
\hline$r(\mathrm{NAO}, \text { wGSNW })_{\mathrm{AMM}, \mathrm{AMOC}}$ & 0.79 & 0.08 & 0.54 & -0.72 & 0.05 \\
\hline$r(\mathrm{AMM}, \mathrm{wGSNW})_{\mathrm{NAO}, \mathrm{AMOC}}$ & 0.64 & -0.30 & 0.87 & -0.50 & 0.04 \\
\hline$r(\mathrm{AMOC}, \mathrm{wGSNW})_{\mathrm{NAO}, \mathrm{AMM}}$ & -0.41 & 0.55 & -0.25 & -0.12 & -0.36 \\
\hline
\end{tabular}

toward Africa. The southeastward propagation is rapid and difficult to see in the snapshots in Fig. 7; however, evidence of this propagation can be seen in the strengthening and broadening equatorial cold anomaly in Figs. 7b-d.

Temperature anomalies that enter the Caribbean Sea become entrained in the mean flow and are carried around Cuba, into the Florida Current, and, finally, the Gulf Stream. A weak temperature response $\left(\sim 0.1^{\circ} \mathrm{C}\right)$ is visible in the Gulf Stream east of Cape Hatteras in December of year 0, while the bulk of the tracer is still found to the east of the Caribbean Sea (Fig. 7b). By the following July, a temperature anomaly with an amplitude of $\sim 0.3^{\circ} \mathrm{C}$ occupies the entirety of the Gulf Stream, and the temperature anomaly in the Straits of Florida is approximately $-0.75^{\circ} \mathrm{C}$ (Fig. 7c). Both of these anomalies are significantly downstream of the passive tracer, indicating that the initial propagation of the anomaly from the tropical Atlantic to the Caribbean is due to waves rather than advection. The temperature anomaly in the Gulf Stream exceeds $-0.5^{\circ} \mathrm{C} 18$ months after the initial perturbation, while the passive tracer is just passing through the Yucatán Channel (Fig. 7d). A video clip of the evolution of the monthly mean temperature anomaly and passive tracer concentration following the vertical velocity perturbation is in the online supplemental material.

Taken in their totality, these results indicate that an Ekman suction perturbation in the tropical Atlantic is capable of producing a temperature perturbation in the Gulf Stream region within 6 months, although the maximum amplitude in the Gulf Stream region occurs
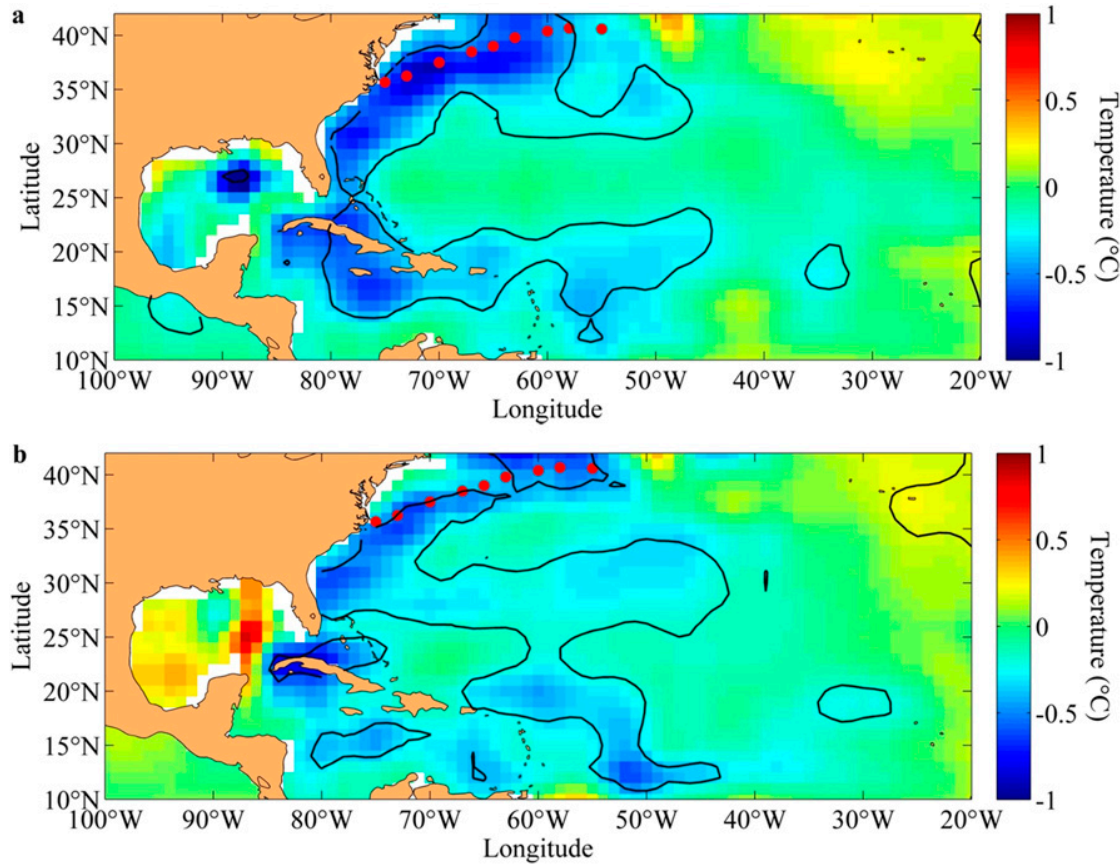

FIG. 2. Differences in annually averaged temperatures at $200 \mathrm{~m}$ between the years in which AMM was in a high state during MAM and the years in which it was in a low state during 19612015 with (a) zero lag between AMM and temperature and (b) AMM leading temperature by one year. Contours enclose areas with $p<0.05$ obtained by a $t$ test. The red dots show the nine locations used to calculate the GSI by Joyce et al. (2009). 


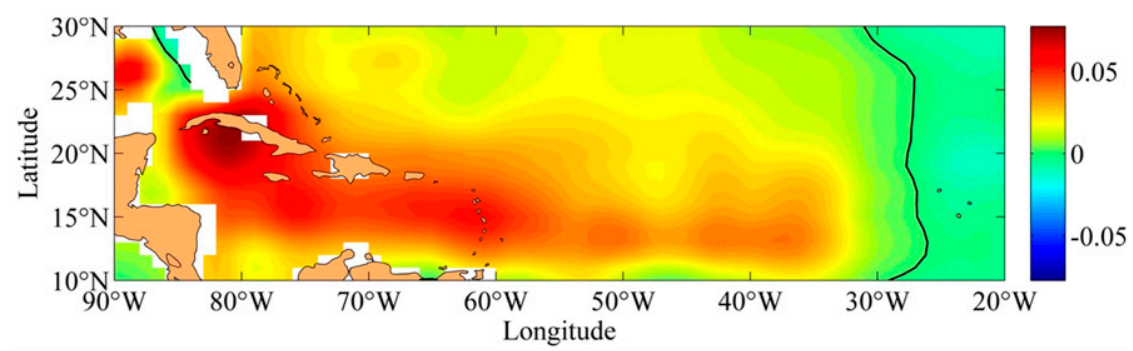

FIG. 3. The leading EOF pattern of annually averaged temperatures at the 200-m depth in tropical North Atlantic $\left(10^{\circ}-30^{\circ} \mathrm{N}, 90^{\circ}-20^{\circ} \mathrm{W}\right)$ during $1961-2015$.

about 18 months later. The fact that the tracer lags behind the temperature signal indicates that the modeled response of the Gulf Stream to AMM perturbations in the tropical Atlantic is initially wave mediated rather than because of advection of temperature anomalies by the mean gyral flow. Once west of $60^{\circ} \mathrm{W}$, both temperature anomalies and the passive tracer are transported advectively; that is, they propagate at the speed of the currents. Temperature anomalies reach the Gulf Stream ahead of the passive tracer primarily because of their wave-mediated propagation in the open ocean.

It is worth mentioning that the resolution of this GCM is a relatively coarse $1^{\circ}$, so the western boundary currents are broad and diffuse-in particular, the peak velocity in the Gulf Stream is too small by a factor of 10 compared to observations. These model results thus significantly underestimate the rate at which anomalies are advected once they reach the western boundary and

a)

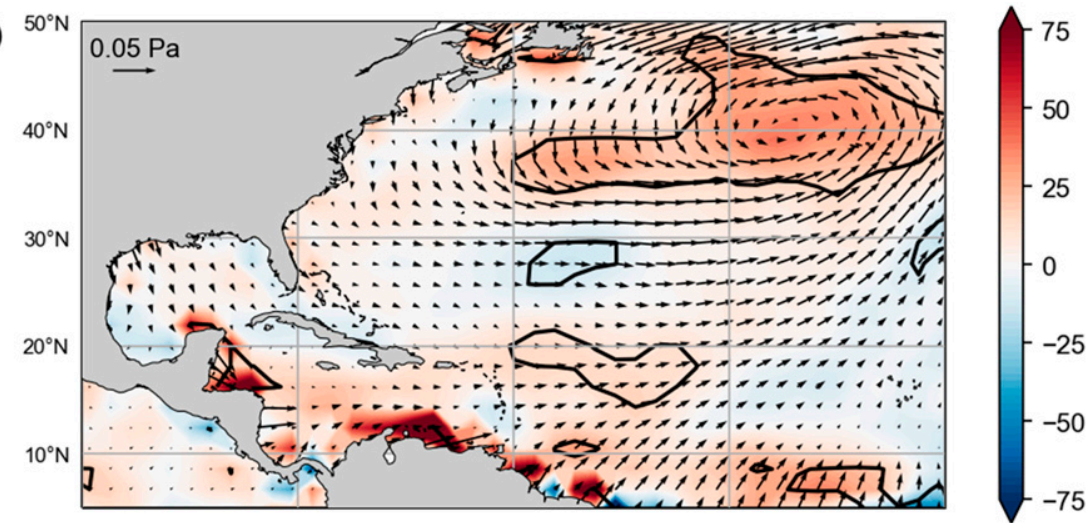

b)

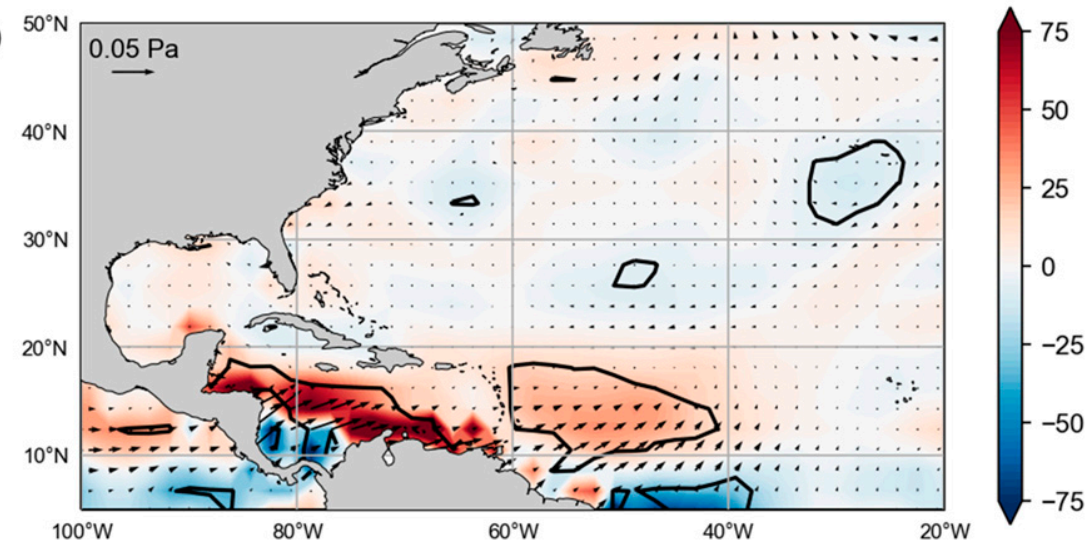

FIG. 4. Differences in Ekman pumping velocity ( $\mathrm{m} \mathrm{yr}^{-1}$; colors) and wind stress (Pa; arrows) in (a) MAM and (b) JJA between years in which the AMM was in high and low states in MAM during 1961-2015. Regions where the difference in the Ekman pumping velocity is statistically significant according to a $t$ test are bounded by black contours. 


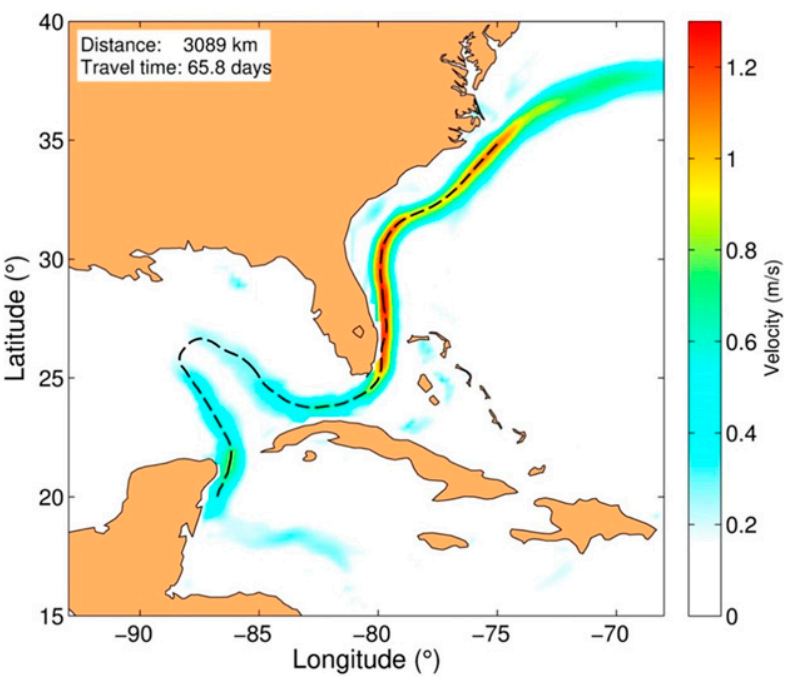

FIG. 5. The position of the GS path averaged for 1993-2015 is marked by a dashed line. The color indicates the mean absolute velocity at $200 \mathrm{~m}$.

therefore represent a lower bound on the time required for advective transport of temperature anomalies. The broad flow to the east of the Caribbean is well represented at coarse resolution, so the initial westward propagation of the anomaly would likely be the same in a higher-resolution experiment.

Ezer (1999) investigated interannual variations of sea level in an ocean circulation model of the Atlantic forced by observed wind and SST anomalies during 1950-89. Westward propagating planetary waves were observed in this model. It was also seen that sea level anomalies in the tropical west Atlantic occur at about the same time as in the Gulf Stream region. Although the AMM was not mentioned in this study, the observation that the sea level anomalies in the western tropics affect the anomalies in the Gulf Stream is broadly consistent with the results of our model study.

\section{Relationships between the North Wall, AMM, and NAO at the surface}

Here we discuss the three indices of the North Wall position at the sea surface. The relationship of climate teleconnections with the eGSI at the sea surface (eGSI0 ) are discussed in section $4 \mathrm{a}$ and those with GSNW and wGSNW are presented in section $4 \mathrm{~b}$.

\section{a. Correlations of eGSI-O with AMM and NAO}

Correlations of eGSI-0 with AMM and NAO, calculated with lags up to 4 years, are shown in Table 3. As seen in row 1 of the table, the correlation with NAO is statistically significant for zero lag. The correlations of (a)

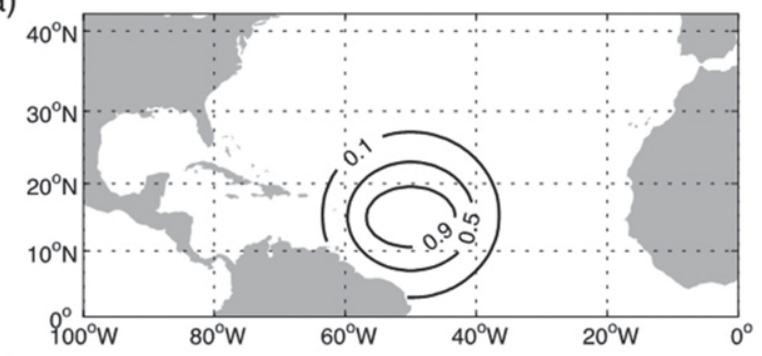

(b)

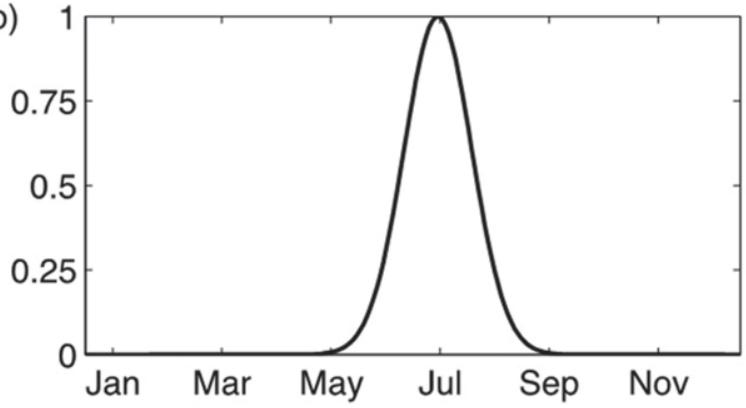

FIG. 6. (a) Spatial footprint and (b) temporal envelope of the vertical velocity perturbation.

AMM with eGSI-0 shown in row 2 are negative and are statistically significant for lags of zero and 1 years.

Both AMM and NAO have statistically significant correlations with eGSI-0 at zero lag, but a significant correlation between AMM and eGSI-0 can also be found at a lag of 1 year. To isolate the effects of each of these indices, we computed partial correlation coefficients shown in the last two rows of Table 3. The results are similar to the simple correlations in rows 1 and 2. Thus, we can infer that at zero lag both NAO and AMM impact eGSI-0 nearly equally, but AMM impacts eGSI-0 with a lag of 1 year also.

\section{b. Correlations of GSNW and wGSNW with AMM and $N A O$}

Correlations of GSNW calculated with lags up to 4 years are shown in Table 4. As seen in row 1 of the table, the correlations with NAO are statistically significant for lags of zero, 1, and 2 years, with NAO leading GSNW, as previously reported by Sanchez-Franks et al. (2016). The correlations of AMM with GSNW shown in row 2 are negative and are statistically significant only for a lag of 1 year. AMM's correlations are smaller than those of NAO.

Partial correlation coefficients are shown in the last two rows of Table 4. In the third row, we see that the correlation between NAO and GSNW remains statistically significant for zero-, 1-, and 2-yr lags when controlled for AMM. On the other hand, the correlation between AMM and GSNW is not statistically significant 


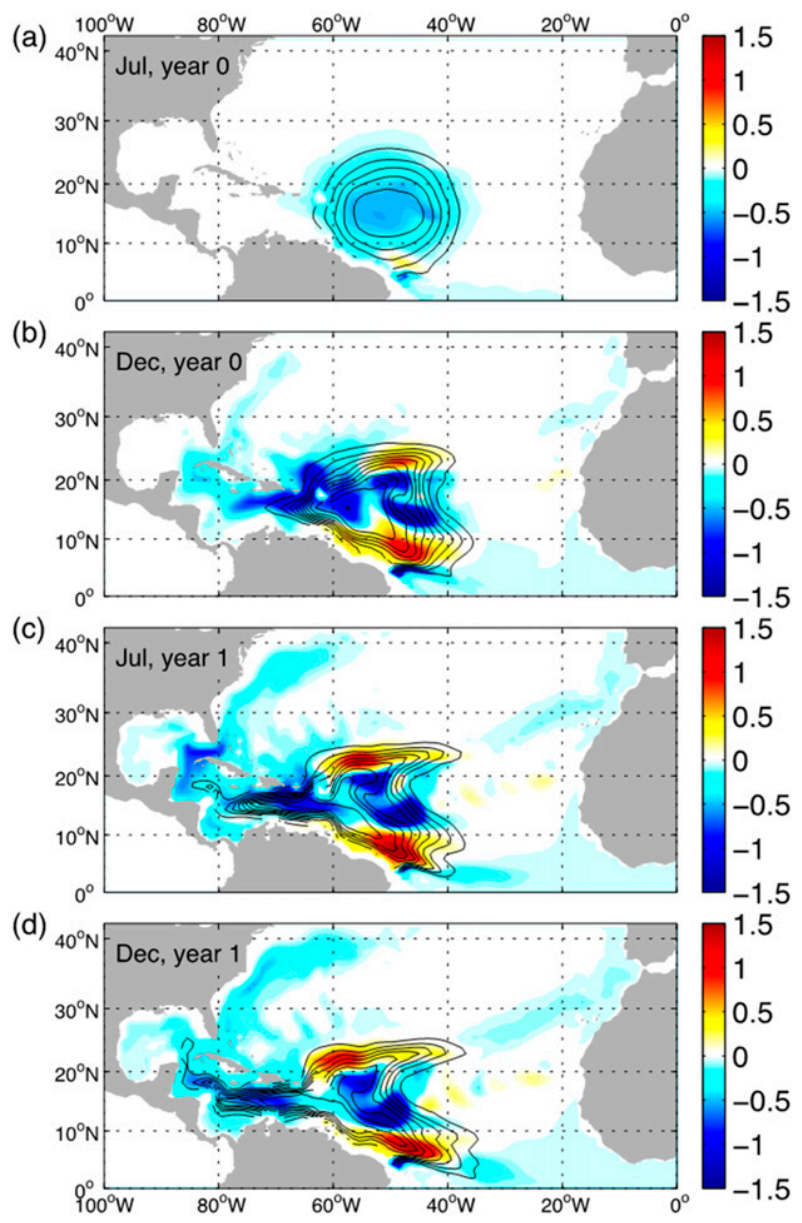

FIG. 7. (a)-(d) Monthly mean temperature anomaly (colors) and passive tracer (contours) at $200 \mathrm{~m}$ following a vertical velocity perturbation. The passive tracer values are entirely negative and have the same initial distribution and units as the temperature perturbation. The contour interval is $0.1^{\circ} \mathrm{C}$; the outermost contour value is $-0.1^{\circ} \mathrm{C}$.

at any lag when controlled for NAO. We conclude that the index GSNW responds to NAO but not to AMM.

The wGSNW presented by Watelet et al. (2017) is an attempt to improve GSNW by using a more objective method of locating the maximum of SST gradient. Correlations of wGSNW are shown in Table 5. As seen in row 1 of the table, the correlation with NAO is statistically significant for the lag of zero years. The correlations of AMM with wGSNW shown in row 2 are statistically significant only for zero lag. Partial correlation coefficients are shown in the last two rows of Table 5. In the third row, we see that the correlation between NAO and wGSNW remains statistically significant for zero lag when controlled for AMM. But the partial correlations of AMM with wGSNW when controlled for NAO are not statistically significant. We conclude that the wGSNW responds to NAO but not to
AMM. The lack of correlation with AMM is consistent between GSNW and wGSNW.

However, GSNW and wGSNW respond differently to NAO. GSNW has statistically significant correlations with NAO at lags of zero, 1 , and 2 years (Table 4, row 1), while for wGSNW, a similar relationship is found only for lag zero. Such differences in response can be expected since interannual variations of GSNW and wGSNW are visibly different, as seen in Fig. 6 of Watelet et al. (2017).

It is to be noted that Watelet et al. (2017) reported a statistically significant relationship between wGSNW and NAO with a lag of 1 year for the period 1940-2014, while the results in Table 5 for 1961-2014 show the relationship with NAO at lag zero. The difference is further discussed in section 5 .

Figure 8 shows the difference in SST composites between AMM high years and low years. It is similar to the well-known tripole pattern for the NAO except with the opposite sign (Wang et al. 2004). When the AMM is in a high state, cooling is observed in the North Wall region, and warm temperature anomalies are observed in the tropics and at high latitudes; the reverse pattern is observed in low-AMM states. The response of SSTs in the Gulf Stream region in this composite is consistent with the negative correlation between AMM and eGSI-0 at zero lag shown in Table 3. However, GSNW and wGSNW, which are derived from the location of the temperature front of the North Wall, are not correlated with AMM, when controlled for NAO, as shown in the last rows of Tables 4 and 5.

\section{Inconsistent correlations with North Wall indices}

By comparing the correlations of eGSI-200 in Table 2 and eGSI-0 in Table 3, we find that the position of North Wall at the surface and at the 200-m depth responds differently to NAO and AMM, even though the same procedure is used in calculating eGSI at both levels. Furthermore, by comparing the results in Tables 3, 4, and 5 we find that the three North Wall indices eGSI-0, GSNW, and wGSNW that aim to quantify its location in sea surface temperatures have different correlations with AMM and NAO. We recall that each index is a principal component that explains a different amount of the North Wall location variance over a different physical domain; it is to be expected that each index yields a different response to external forcing. This conclusion can also be deduced from Table 2 of Watelet et al. (2017), in which correlations of NAO with North Wall indices calculated by eight authors are seen to disagree.

However, some of the inconsistencies in correlations reported in the literature can be due to the different 


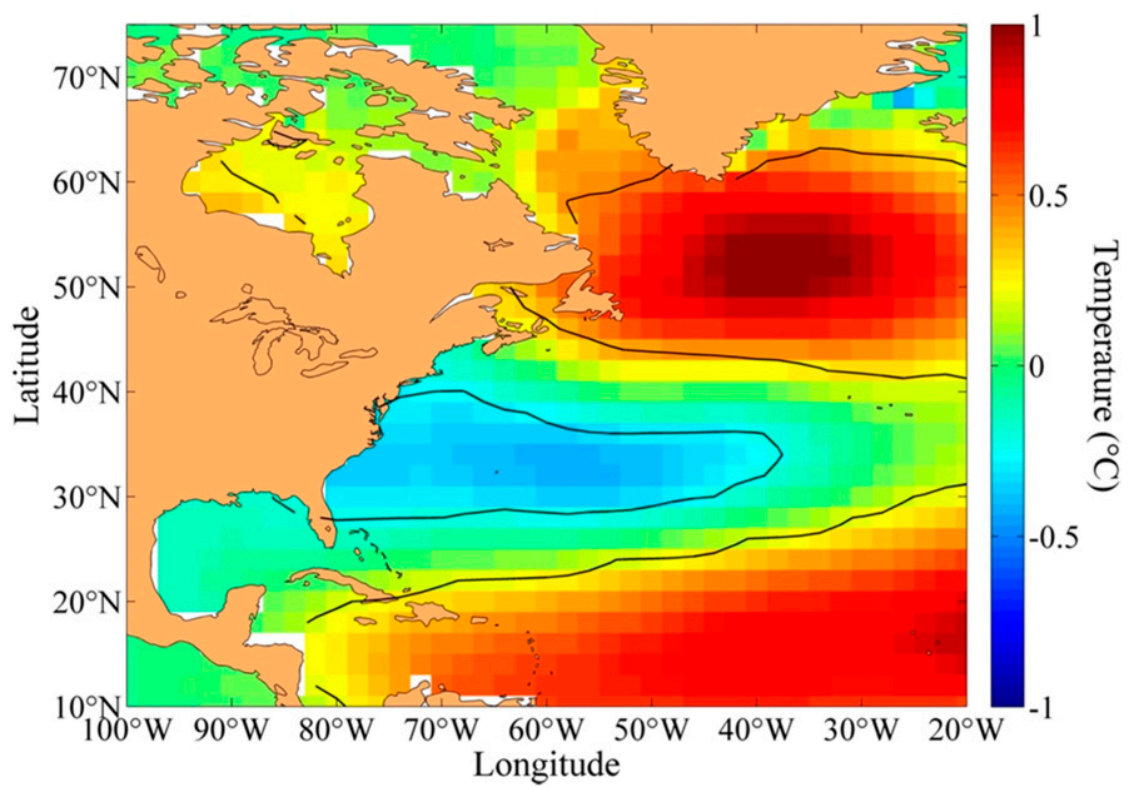

FIG. 8. Composite differences between annually averaged sea surface temperature between AMM high and low states during 1961-2015. Regions where the difference is statistically significant according to a $t$ test are bounded by black contours.

choices made by the authors in factors that can contribute to the value of the correlation coefficient between two variables. Even if the same index of the North Wall is used, its correlation with the NAO can be affected by

1) the length of the time series,

2) the period over which correlations are calculated,

3) autocorrelation in the data unless it is removed,

4) the definition of the NAO, and

5) whether seasonal or annual averages are used.

The effects of choices made in computing the correlations are compared in Table 6 for the North Wall index wGSNW. NAO values given by Hurrell et al. (2003) as the leading principal component of SLP in the North Atlantic are compared to those given by Climate Prediction Center (CPC), which is the first principal component of 500-hPa geopotential height anomalies. Row 1 gives the results of the calculation as reported by Watelet et al. (2017) for 1940-2014; the annually averaged NAO of Hurrell (1995) is used without detrending the data. A statistically significant correlation of 0.37 is obtained at lag 1 in agreement with Watelet et al. (2017). Keeping every factor the same but choosing NAO averaged over the DJF season gives a higher correlation at lag zero, and correlation at lag 1 is not statistically significant. Comparing the different rows in Table 6 shows that the two NAO definitions do not make a significant difference in the result and neither does detrending of the data. However, it is consistently seen that NAO (DJF) gives a higher value of the correlation coefficient than its annually averaged version. Also, the annual NAO gives a statistically significant correlation at a lag of 1 year, while for the DJF NAO the significant correlation occurs at lag zero.

\section{Relationship between the AMM and North Wall below $200 \mathrm{~m}$}

Ekman forcing induced by the AMM creates a perturbation of vertical velocity in the tropics, and the resulting change in the temperature profile is given by

$$
\frac{\partial \theta}{\partial t}=-w \frac{\partial \theta}{\partial z}
$$

where $\theta$ is temperature and $w$ is vertical velocity. For a given $w$, the temperature change is largest where the vertical derivative of temperature is largest. We see from Fig. 9 that the vertical temperature gradient peaks near $200 \mathrm{~m}$ and decreases rapidly with depth above and below this level. This suggests that the temperature perturbation induced by AMM should peak near the 200-m depth in the tropical Atlantic.

This inference is consistent with the AMM-conditioned composites of temperature at $200 \mathrm{~m}$ in Figs. $2 \mathrm{a}$ and $2 \mathrm{~b}$ showing cooling in the tropics. The AMM-based composite of surface temperature in Fig. 8 shows warming 



FIG. 9. (left) Temperature $\theta$ and (right) its vertical gradient $\theta_{z}$ averaged over $14^{\circ}-22^{\circ} \mathrm{N}, 50^{\circ}-60^{\circ} \mathrm{W}$ for $1961-2015$ from the EN4 dataset.

instead of cooling at the surface in the tropical Atlantic. A composite of temperature at the $300-\mathrm{m}$ depth is presented in Fig. 10, and it shows weak cooling (not statistically significant) in the tropics. Composite temperature differences at deeper levels (not shown) also do not indicate significant cooling in the tropical North Atlantic in response to AMM. The significant cooling of temperatures in the tropics induced by AMM is near $200 \mathrm{~m}$, and the processes that transfer this signal to the North Wall were discussed in section $3 \mathrm{~b}$.

A statistically significant cooling signal of AMM in the North Wall region is seen at the surface in Fig. 8 and at $300 \mathrm{~m}$ in Fig. 10. It extends to greater depths, as shown in Fig. 11a. The strongest correlations are at lags of $0-1$ years extending from surface to about $300 \mathrm{~m}$, then decreasing in magnitude to about $600 \mathrm{~m}$, and then increasing again at lower depth where the lags are in the range of 1-3 years. For comparison, Fig. 11b shows correlations of NAO with eGSI. Correlations near the surface are at lags of $0-1$ years and become weak near the 200-m depth. Strong correlations between NAO and eGSI are found between 300 and $900 \mathrm{~m}$. An interesting feature of this relationship is that the lag increases gradually with depth, being from zero to 1 years near the surface and about 2-4 years between near $900 \mathrm{~m}$.

Figure 11c shows the partial correlations of AMM with eGSI when controlled for the NAO. It indicates that the cooling in the North Wall originating in the tropics that can be attributed to AMM is seen from the surface to about $500 \mathrm{~m}$ with lags of zero and 1 years. A weaker signal of AMM is found in the range of 700 $1000 \mathrm{~m}$ at the lag of 1 year.

Figure 11d displays the partial correlation between NAO and eGSI when controlled for AMM. There is no significant correlation above $300 \mathrm{~m}$ except at the surface with zero lag. Strong partial correlations between NAO and eGSI occur between 300 and $500 \mathrm{~m}$ with lags of 1 and 2 years. Between 500 and $900 \mathrm{~m}$ the lags are near 2-3 years.

Comparison of Figs. 11c and 11d shows that the impact of AMM on eGSI is the dominant influence from the surface to about $300 \mathrm{~m}$. Both AMM and NAO contribute to the variation of the North Wall in the range of $300-500 \mathrm{~m}$, while the NAO is the dominant influence at lower depths.

To investigate how a response to AMM in the North Wall occurs below $200 \mathrm{~m}$, we computed partial correlations of AMM (controlling for NAO) with temperature at depths along the path of the Gulf Stream. Correlations with lags of zero and 1 years, respectively, are shown in Figs. 12a and 12b. In Fig. 12a, we see that a statistically significant response to AMM reaches to about $400-500 \mathrm{~m}$ off the shelf after the Gulf Stream detaches from the coast. The cooling should not be interpreted as a diabatic effect but rather as an indication that the Gulf Stream axis has shifted south, allowing cooler slope seawater to occupy the mean path of the Gulf Stream, as has been suggested by Rossby and Benway (2000), Rossby et al. (2010), and Peña-Molino and Joyce (2008) and also seen in the results of Ezer et al. (2013) and Ezer (2015).

One year later, in Fig. 12b, the direct influence of AMM is confined to a layer near $200 \mathrm{~m}$ extending about $1000 \mathrm{~km}$ from Cape Hatteras.

We interpret this southward shift to be due to the shoaling of isothermal surfaces in the range of $15^{\circ}-18^{\circ} \mathrm{C}$ in the western Atlantic in response to Ekman suction anomalies in the Caribbean and tropical Atlantic. These surfaces are steeply inclined in the Gulf Stream, so vertical motion results in a horizontal migration of the point where these surfaces pass through a given depth. In particular, the shoaling of $15^{\circ} \mathrm{C}$ isothermal surface 


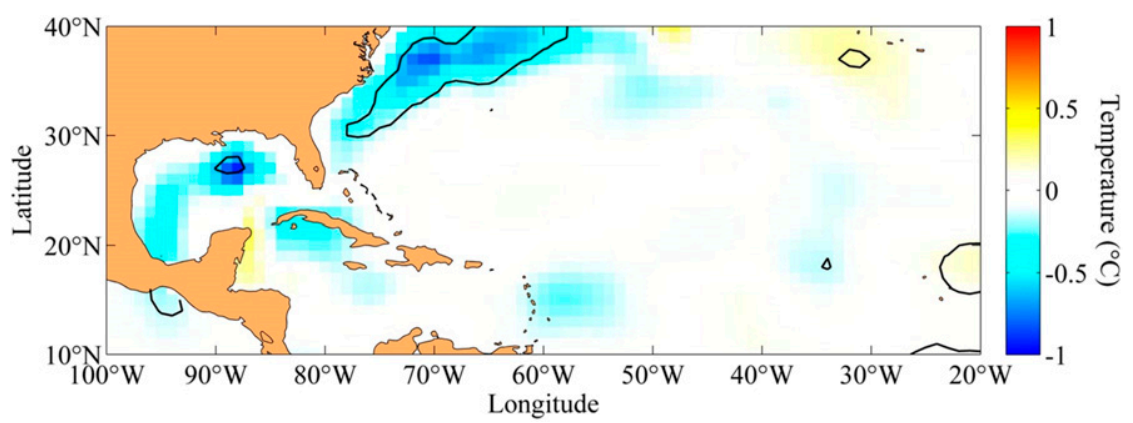

FIG. 10. Composite differences between annually averaged temperature at $300 \mathrm{~m}$ between AMM high and low states during 1961-2015. Regions where the difference is statistically significant according to a $t$ test are bounded by black contours.

near the Gulf Stream results in a southward migration of the $15^{\circ} \mathrm{C}$ isotherm at the $200-\mathrm{m}$ depth, which is reflected in negative values of the eGSI-200.

We can ask if downward mixing in the Gulf Stream contributes to the cooling at the depth seen in Fig. 12a. Whalen et al. (2012) used strain information from Argo float profiles in the upper $2000 \mathrm{~m}$ to generate estimates of energy dissipation rate and diffusivity. In their Fig. 2a, the diffusion coefficient in the Gulf Stream region in the 250-500-m layer is $\sim 10^{-4} \mathrm{~m}^{2} \mathrm{~s}^{-1}$. This implies a vertical mixing time of about 3 years over $100 \mathrm{~m}$, indicating that downward mixing is unlikely to be significant factor in the North Wall.

\section{Relationship between the AMOC and the North Wall during 2005-15}

a. Correlations of eGSI at $200 \mathrm{~m}$ with AMOC, AMM, and $N A O$

Continuous data for AMOC are available since April 2004 and the eGSI time series extends to 2015. Thus, annual averages of the two variables are available for the 11-yr period 2005-15. The correlations between them are shown in Table 7. Because the sample size is only 11 at zero lag and decreases with an increase in lag, the effective sample size for statistical significance test described in section 2 is not applied here. None of the correlations of eGSI-200 with AMM, NAO, and AMOC are statistically significant. All partial correlations are also insignificant and are not shown.

To increase the sample size, seasonal averages of eGSI-200, AMM, NAO, and AMOC were calculated. The seasons are defined as JFM, AMJ, JAS, and OND. The sample size is now 44 at zero lag, but the seasonal data are autocorrelated, which reduces the effective sample size. The correlations of eGSI-200 with AMOC and NAO in Table 8 are not statistically significant, but the correlation of AMM with eGSI-200 is significant with a lag of 2 seasons. When partial correlations are calculated, we find that the correlation of eGSI-200 with AMM is marginally significant $(0.05<p<0.1)$ at lags of 2 and 3 seasons when controlled for NAO and AMOC. Correlations between AMOC and eGSI-200 are not statistically significant.

\section{b. Correlations of North Wall at the surface with $A M O C, A M M$, and NAO}

The correlations of eGSI-0, GSNW, and wGSNW with AMM, NAO, and AMOC are now discussed. Only annually averaged values of wGSNW are available. Table 9 shows correlations of annually averaged eGSI0 with NAO, AMM, and AMOC. Only the correlation of NAO with eGSI-0 at zero lag is statistically significant. However, it becomes smaller and insignificant when controlled for AMM and AMOC in the calculation of partial correlation coefficients. Thus, the annually averaged eGSI-0 is not correlated with AMM, AMOC, or NAO during 2005-15.

Correlations of GSNW with NAO, AMM, and AMOC are given in Table 10. This North Wall index is available only until 2014 , so the sample size is 10 at zero lag. The table shows that while the correlation of GSNW with NAO is not statistically significant, that with AMM is significant at a lag of 2 years and that with AMOC is significant at a 1-yr lag. The partial correlations of GSNW with NAO and AMM are statistically significant with a lag of 2 years, while that with AMOC is significant at lags of 1 and 2 years.

Table 11 lists the correlations of wGSNW with NAO, AMM, and AMOC. Simple correlations with NAO are not statistically significant. AMM has a statistically significant correlation with wGSNW at a lag of 2 years, while the correlations of AMOC with wGSNW are not statistically significant. The partial correlation of NAO with wGSNW when controlled for AMM and AMOC is statistically significant at zero lag. Partial correlation of 

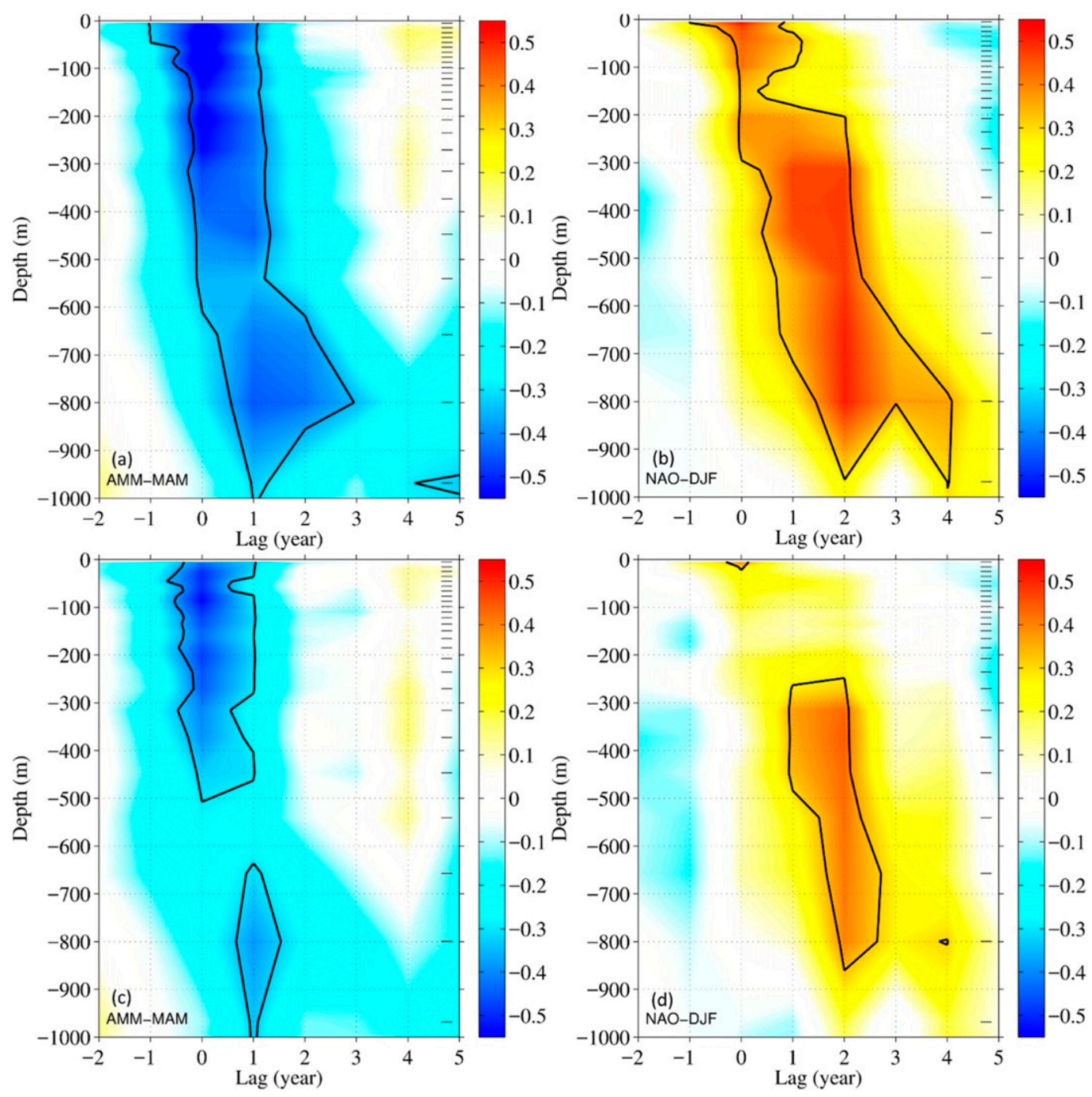

FIG. 11. (a) Correlation of AMM with the eGSI as a function of depth. (b) Correlation of NAO with eGSI as a function of depth. (c) Partial correlation of AMM with the eGSI controlled for the NAO. (d) Partial correlation of NAO with the eGSI controlled for the AMM. The correlations are for 1961-2015. Contours enclose areas with statistical significance.

the AMM with wGSNW when controlled for NAO and AMOC is statistically significant at a lag of 2 years. The AMOC is not correlated with wGSNW.

Comparing Tables 9 and 10, we notice that the responses of GSNW and wGSNW to teleconnections are not consistent with each other during the period 200514 , although wGSNW aims to capture the same aspects of the North Wall as GSNW. The eGSI-0 is also a measure of North Wall location in SSTs, and Table 9 shows that its correlations with NAO, AMM, and AMOC are different from those of GSNW and wGSNW.

Based on these results for annual averages of North Wall indices at the sea surface, we see that the GSNW responds to $\mathrm{AMOC}$ at lags of 1 and 2 years, but
wGSNW, eGSI-0, and GSI are not related to AMOC. Usefulness of these results is limited by the short duration for which AMOC transport data have been collected so far.

\section{Conclusions}

Results presented in this paper show that the Atlantic meridional mode (AMM) is the dominant influence on interannual variations of the North Wall of the Gulf Stream from the ocean surface to a depth of about $300 \mathrm{~m}$, the NAO is the major influence between 500 and $1000 \mathrm{~m}$, and both the teleconnections play roles in modulating the North Wall in the intermediate layer. 

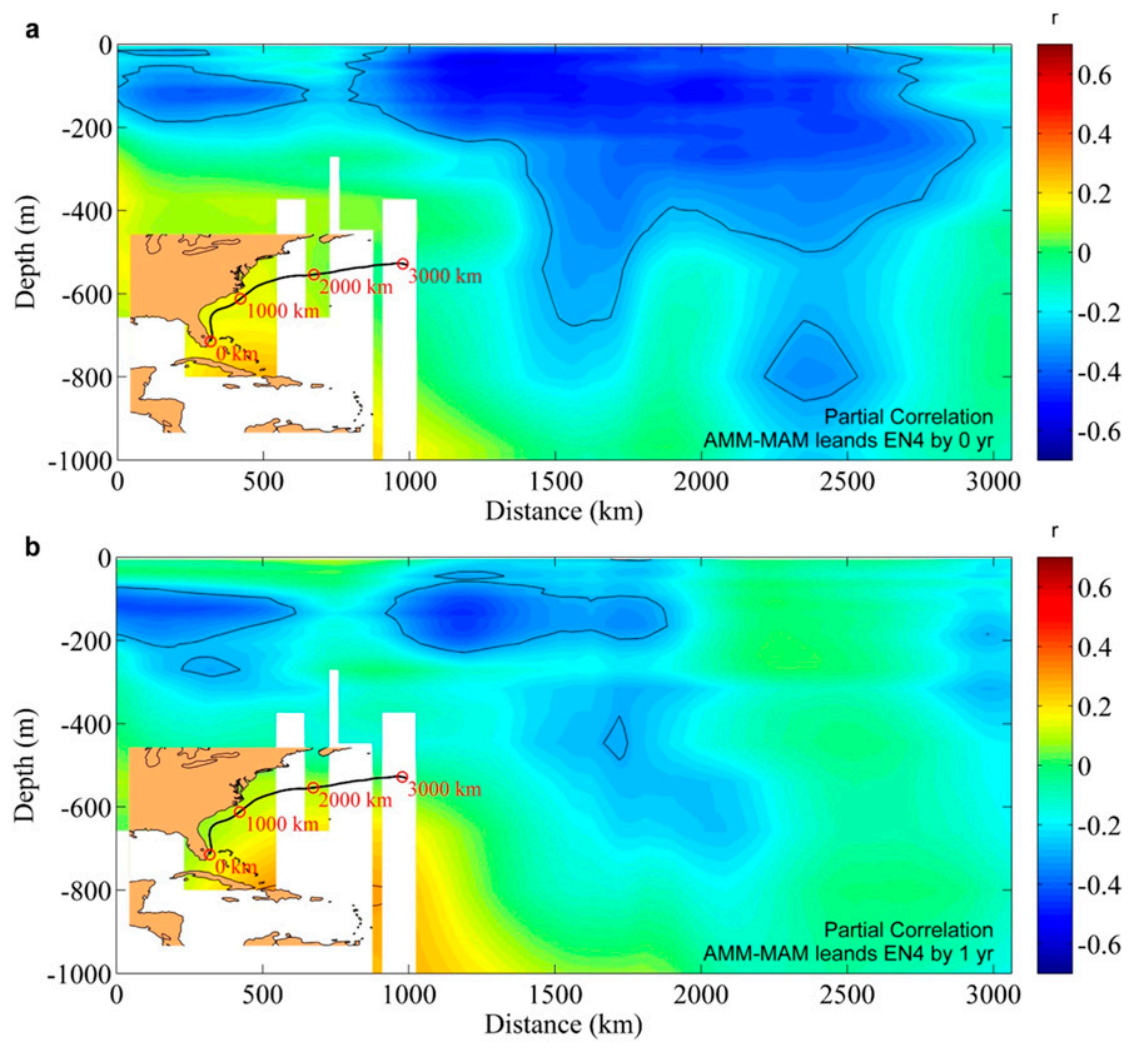

FIG. 12. Partial correlation between AMM and temperature (controlled for the NAO) in the Gulf Stream along its path during 1961-2015 (a) at zero lag and (b) when the AMM leads temperatures by one year. The Gulf Stream path is shown in the lower left in both figures.

We also see significant influence from both $\mathrm{AMM}$ and $\mathrm{NAO}$ at the surface.

Evidence is presented that suggests that Ekman suction shoals isotherms near the tropical thermocline when the AMM is in a positive phase. This shoaling signal propagates through the Caribbean and leads a southward shift of the North Wall. The shoaling of isotherms manifests a cooling signal in the tropics near 200-m depth, while the southward migration of the North Wall appears as a cooling signal at fixed latitude over a range of depths. The AMM signal impacts the North Wall position within the year by advection. Another signal is initially carried by planetary waves generated in the tropics, which create temperature anomalies that are advected through the Caribbean Sea and reach the North Wall about a year later.

Using AMOC transport data for 2005-15, its relationship with the North Wall was compared with those of NAO and AMM. In annual data, the AMOC was found to be correlated with one of three North Wall indices at the sea surface and not correlated with the North Wall at $200 \mathrm{~m}$. In seasonally resolved data also, the correlation of AMOC with the North Wall at $200 \mathrm{~m}$ is not statistically significant.

The correlation between NAO anomalies and the Gulf Stream North Wall depends on whether annually averaged or winter (DJF) values of the NAO are considered. The correlation is consistently higher when the DJF average is used. In addition, correlations between NAO and the different North Wall indices disagree. The likely reason for this inconsistency is that each North Wall index is calculated by EOF analysis of data over a different domain and time period, and therefore the principal component that defines each index captures a different amount of the North Wall variance.

Acknowledgments. This work was supported by the National Science Foundation Grant (OCE-1634829). The development of the model was also supported by the NSF under Grant OCE-1258887, and computational resources were provided by the Texas Advanced Computing Center and the San Diego Supercomputer Center through XSEDE. NCEP Reanalysis data provided by the NOAA/OAR/ESRL PSD from their website (https://www.ersl.noaa.gov/psd). 


\section{APPENDIX}

\section{Description of the Global Circulation Model}

The ocean model used here is described by Wolfe et al. (2017), where a detailed description of its configuration and properties are given. Briefly, the model is based on the ECCO, version 4 (ECCOv4; Forget et al. 2015), configuration of the MIT general circulation model (MITgcm; Marshall et al. 1997a,b) and has a global latitude/longitude/polar cap topology, a $1^{\circ}$ nominal horizontal resolution that telescopes to $13^{\circ}$ near the equator, and 50 vertical levels. The physics include dynamic sea ice and the KPP mixed layer parameterization (Large et al. 1994). The Gent-McWilliams (GM; Gent and McWilliams 1990) parameterization of mesoscale eddies is implemented using the boundary value problem approach of Ferrari et al. 2010). We use spatially constant GM and isopycnal Redi (1982) diffusivities of $500 \mathrm{~m}^{2} \mathrm{~s}^{-1}$. In the interior, the diapycnal diffusivity is quite small $\left(k_{v}=10^{-5} \mathrm{~m}^{2} \mathrm{~s}^{-1}\right)$, and the advection scheme is the nearly adiabatic scheme of Prather (1986). The surface forcing is obtained from the annually repeating CORE normal-year forcing atmospheric state of Large and Yeager (2009), version 2, using the bulk formulas of Large and Yeager (2004), with additional forcing in the form of a relaxation of sea surface salinity to an annually repeating monthly sea surface salinity climatology described in Forget et al. (2015) over a time scale of 300 days. The total forcing thus contains a broad spectrum of variability whose longest period is one year. The model was spun up to a statistical steady state over approximately 4800 years.

\section{REFERENCES}

Amaya, D. J., M. J. DeFlorio, A. J. Miller, and S.-P. Xie, 2017: WES feedback and the Atlantic meridional mode: Observations and CMIP5 comparisons. Climate Dyn., 49, 1665-1679, https://doi.org/10.1007/s00382-016-3411-1.

Borkman, D. G., and T. J. Smayda, 2009: Gulf Stream position and winter NAO as drivers of long-term variations in the bloom phenology of the diatom Skeletonema costatum "speciescomplex" in Narragansett Bay, RI, USA. J. Plankton Res., 31, 1407-1425, https://doi.org/10.1093/plankt/fbp072.

Boyer, T. P., and Coauthors, 2013: World Ocean Database 2013. NOAA Atlas NESDIS 72, 208 pp.

Bryan, F. O., M. W. Hecht, and R. D. Smith, 2007: Resolution convergence and sensitivity studies with North Atlantic circulation models. Part I: The western boundary current system. Ocean Modell., 16, 141-159, https://doi.org/10.1016/j.ocemod.2006.08.005.

Chassignet, E. P., and D. P. Marshall, 2008: Gulf Stream separation in numerical ocean models. Ocean Modeling in an Eddying Regime, Geophys. Monogr., Vol. 177, Amer. Geophys. Union, 39-61, https://doi.org/10.1029/177GM05.

Chaudhuri, A. H., A. Gangopadhyay, and J. J. Bisagni, 2011: Response of the Gulf Stream transport to characteristic high and low phases of the North Atlantic Oscillation. Ocean Modell., 39, 220-232, https://doi.org/10.1016/j.ocemod.2011.04.005.

Chiang, J. C. H., and D. J. Vimont, 2004: Analogous Pacific and Atlantic meridional modes of tropical atmosphere-ocean variability. J. Climate, 17, 4143-4158, https://doi.org/10.1175/ JCLI4953.1.

Cipollini, P., D. Cromwell, P. G. Challenor, and S. Raffaglio, 2001: Rossby waves detected in global ocean color data. Geophys. Res. Lett., 28, 323-326, https://doi.org/10.1029/1999GL011231.

Copernicus Marine Environmental Monitoring Service, 2017: Global ARMOR3. Copernicus Marine Environmental Monitoring Service, accessed 6 June 2018, http://marine.copernicus. $\mathrm{eu} /$ services-portfolio/access-to-products/?option $=$ com_csw\&view $=$ details\&product_id=MULTIOBS_GLO_PHY_REP_015_002.

Cornillon, P., and R. Watts, 1987: Satellite thermal infrared and inverted echo sounder determinations of the Gulf Stream northern edge. J. Atmos. Oceanic Technol., 4, 712-723, https:// doi.org/10.1175/1520-0426(1987)004<0712:STIAIE >2.0.CO;2.

Drinkwater, K. F., R. A. Myers, R. G. Pettipas, and T. L. Wright, 1994: Climatic data for the northwest Atlantic: The position of the shelf/slope front and the northern boundary of the Gulf Stream between $50^{\circ} \mathrm{W}$ and $75^{\circ} \mathrm{W}, 1973-1992$. Canadian Hydrography and Ocean Sciences Data Rep. 125, 103 pp.

Ezer, T., 1999: Decadal variabilities of the upper layers of the subtropical North Atlantic: An ocean model study. J. Phys. Oceanogr., 29, 3111-3124, https://doi.org/10.1175/ 1520-0485(1999)029<3111:DVOTUL > 2.0.CO;2.

_ 2015: Detecting changes in the transport of the Gulf Stream and the Atlantic overturning circulation from coastal sea level data: The extreme decline in 2009-2010 and estimated variations for 1935-2012. Global Planet. Change, 129, 23-36, https:// doi.org/10.1016/j.gloplacha.2015.03.002.

_ L. P. Atkinson, W. B. Corlett, and J. L. Blanco, 2013: Gulf Stream's induced sea level rise and variability along the U.S. mid-Atlantic coast. J. Geophys. Res., 118, 685-697, https://doi.org/ 10.1002/jgrc.20091.

Ferrari, R., S. M. Griffies, A. J. G. Nurser, and G. K. Vallis, 2010: A boundary-value problem for the parameterized mesoscale eddy transport. Ocean Modell., 32, 143-156, https://doi.org/ 10.1016/j.ocemod.2010.01.004.

Forget, G., J.-M. Campin, P. Heimbach, C. N. Hill, R. M. Ponte, and C. Wunsch, 2015: ECCO version 4: An integrated framework for non-linear inverse modeling and global ocean state estimation. Geosci. Model Dev., 8, 3071-3104, https://doi.org/ 10.5194/gmd-8-3071-2015.

Frankignoul, C., G. D. Coëtlogon, T. M. Joyce, and S. Dong, 2001: Gulf Stream variability and ocean-atmosphere interactions. J. Phys. Oceanogr., 31, 3516-3529, https://doi.org/10.1175/ 1520-0485(2002)031<3516:GSVAOA > 2.0.CO;2.

Fuglister, F. C., 1955: Alternative analyses of current surveys. Deep-Sea Res., 2, 213-229, https://doi.org/10.1016/0146-6313(55)90026-5.

Gangopadhyay, A., P. Cornillon, and D. R. Watts, 1992: A test of the Parsons-Veronis hypothesis on the separation of the Gulf Stream. J. Phys. Oceanogr., 22, 1286-1301, https://doi.org/ 10.1175/1520-0485(1992)022<1286:ATOTPH > 2.0.CO;2.

— A. Chaudhuri, and A. Taylor, 2016: On the nature of temporal variability of the Gulf Stream path from $75^{\circ}$ to $55^{\circ} \mathrm{W}$. Earth Interact., 20, https://doi.org/10.1175/EI-D-15-0025.1.

Gent, P. R., and J. C. McWilliams, 1990: Isopycnal mixing in ocean circulation models. J. Phys. Oceanogr., 20, 150-155, https://doi.org/ 10.1175/1520-0485(1990)020<0150:IMIOCM > 2.0.CO;2.

Goddard, P. B., J. Yin, S. M. Griffies, and S. Zhang, 2015: An extreme event of sea-level rise along the northeast coast of North 
America in 2009-2010. Nat. Commun., 6, 6346, https://doi.org/ $10.1038 /$ ncomms 7346 .

Godfrey, J. S., 1975: On ocean spindown I: A linear experiment. J. Phys. Oceanogr., 5, 399-409, https://doi.org/10.1175/ 1520-0485(1975)005<0399:OOSIAL $>2.0 . \mathrm{CO} ; 2$.

Good, S. A., M. J. Martin, and N. A. Rayner, 2013: EN4: Quality controlled ocean temperature and salinity profiles and monthly objective analyses with uncertainty estimates. J. Geophys. Res. Oceans, 118, 6704-6716, https://doi.org/10.1002/2013JC009067.

Hamby, D. M., 1994: A review of techniques for parameter sensitivity analysis of environmental models. Environ. Monit. Assess., 32, 135-154, https://doi.org/10.1007/BF00547132.

Hameed, S., and S. Piontkovski, 2004: The dominant influence of the Icelandic low on the position of the Gulf Stream northwall. Geophys. Res. Lett., 31, L09303, https://doi.org/10.1029/ 2004 GL019561.

Hurrell, J. W., 1995: Decadal trends in the North Atlantic Oscillation: Regional temperatures and precipitation. Science, $\mathbf{2 6 9}$, 676-679, https://doi.org/10.1126/science.269.5224.676.

_- Y. Kushnir, G. Ottersen, and M. Visbeck, 2003: An overview of the North Atlantic Oscillation. The North Atlantic Oscillation: Climatic Significance and Environmental Impact, Geophys. Monogr., Vol. 134, Amer. Geophys. Union, 1-35, https://doi.org/10.1029/134GM01.

Jennings, E., and N. Allott, 2006: Position of the Gulf Stream influences lake nitrate concentrations in SW Ireland. Aquat. Sci., 68, 482-489, https://doi.org/10.1007/s00027-006-0847-0.

Joyce, T. M., and R. Zhang, 2010: On the path of the Gulf Stream and the Atlantic meridional overturning circulation. J. Climate, 23, 3146-3154, https://doi.org/10.1175/ 2010JCLI3310.1.

—, C. Deser, and M. A. Spall, 2000: The relation between decadal variability of subtropical mode water and the North Atlantic Oscillation. J. Climate, 13, 2550-2569, https://doi.org/ 10.1175/1520-0442(2000)013<2550:TRBDVO > 2.0.CO;2.

_ - Y.-O. Kwon, and L. Yu, 2009: On the relationship between synoptic wintertime atmospheric variability and path shifts in the Gulf Stream and the Kuroshio Extension. J. Climate, 22, 3177-3192, https://doi.org/10.1175/2008JCLI2690.1.

Kalnay, E., and Coauthors, 1996: The NCEP/NCAR 40-Year Reanalysis Project. Bull. Amer. Meteor. Soc., 77, 437-471, https:// doi.org/10.1175/1520-0477(1996)077<0437:TNYRP $>2$.0.CO;2.

Kushnir, Y., W. A. Robinson, P. Chang, and A. W. Robertson, 2006: The physical basis for predicting Atlantic sector seasonal-to-interannual climate variability. J. Climate, 19, 5949-5970, https://doi.org/10.1175/JCLI3943.1.

Large, W. G., and S. G. Yeager, 2004: Diurnal to decadal global forcing for ocean and sea-ice models: The data sets and flux climatologies. NCAR Tech. Note NCAR/TN-460+STR, 105 pp.

— and - 2009: The global climatology of an interannually varying air-sea flux data set. Climate Dyn., 33, 341-364, https:// doi.org/10.1007/s00382-008-0441-3.

— J. C. McWilliams, and S. C. Doney, 1994: Oceanic vertical mixing: A review and a model with a nonlocal boundary layer parameterization. Rev. Geophys., 32, 363-403, https://doi.org/ 10.1029/94RG01872.

Lillibridge, J. L., III, and A. J. Mariano, 2013: A statistical analysis of Gulf Stream variability from $18+$ years of altimetry data. Deep-Sea Res. II, 85, 127-146, https://doi.org/ 10.1016/j.dsr2.2012.07.034.

Liu, Z., L. Wu, and E. Bayler, 1999: Rossby wave-coastal Kelvin wave interaction in the extratropics. Part I: Lowfrequency adjustment in a closed basin. J. Phys. Oceanogr.,
29, 2382-2404, https://doi.org/10.1175/1520-0485(1999)029<2382: RWCKWI $>2.0 . C O ; 2$.

Marshall, J., A. Adcroft, C. Hill, L. Perelman, and C. Heisey, 1997a: A finite-volume, incompressible Navier Stokes model for studies of the ocean on parallel computers. J. Geophys. Res., 102, 5753-5766, https://doi.org/10.1029/96JC02775.

— C. Hill, L. Perelman, and A. Adcroft, 1997b: Hydrostatic, quasi-hydrostatic, and nonhydrostatic ocean modeling. J. Geophys. Res., 102, 5733-5752, https://doi.org/10.1029/ 96JC02776.

McCarthy, G. D., and Coauthors, 2015: Measuring the Atlantic meridional overturning circulation at $26^{\circ}$ N. Prog. Oceanogr., 130, 91-111, https://doi.org/10.1016/j.pocean.2014.10.006.

Nye, J. A., T. M. Joyce, Y.-O. Kwon, and J. S. Link, 2011: Silver hake tracks changes in Northwest Atlantic circulation. Nat. Commun., 2, 412, https://doi.org/10.1038/ncomms1420.

Patricola, C. M., R. Saravanan, and P. Chang, 2014: The impact of the El Niño-Southern Oscillation and Atlantic meridional mode on seasonal Atlantic tropical cyclone activity. J. Climate, 27, 5311-5328, https://doi.org/ 10.1175/JCLI-D-13-00687.1.

Peña-Molino, B., and T. M. Joyce, 2008: Variability in the slope water and its relation to the Gulf Stream path. Geophys. Res. Lett., 35, L03606, https://doi.org/10.1029/2007GL032183.

Pérez-Hernández, M. D., and T. M. Joyce, 2014: Two modes of Gulf Stream variability revealed in the last two decades of satellite altimeter data. J. Phys. Oceanogr., 44, 149-163, https://doi.org/10.1175/JPO-D-13-0136.1.

Pickart, R. S., M. A. Spall, and J. R. N. Lazier, 1997: Mid-depth ventilation in the western boundary current system of the subpolar gyre. Deep-Sea Res. I, 44, 1025-1054, https://doi.org/ 10.1016/S0967-0637(96)00122-7.

Planque, B., and A. H. Taylor, 1998: Long-term changes in zooplankton and the climate of the North Atlantic. ICES J. Mar. Sci., 55, 644-654, https://doi.org/10.1006/jmsc.1998.0390.

Prather, M. J., 1986: Numerical advection by conservation of second-order moments. J. Geophys. Res., 91, 6671-6681, https://doi.org/10.1029/JD091iD06p06671.

Quenouille, M. H., 1952: Associated Measurements. Butterworths, 241 pp.

Redi, M. H., 1982: Oceanic isopycnal mixing by coordinate rotation. J. Phys. Oceanogr., 12, 1154-1158, https://doi.org/ 10.1175/1520-0485(1982)012<1154:OIMBCR >2.0.CO;2.

Rossby, T., 1999: On gyre interactions. Deep-Sea Res. II, 46, 139164, https://doi.org/10.1016/S0967-0645(98)00095-2.

_ , and R. L. Benway, 2000: Slow variations in mean path of the Gulf Stream east of Cape Hatteras. Geophys. Res. Lett., 27, 117-120, https://doi.org/10.1029/1999GL002356.

_ C. Flagg, and K. Donohue, 2010: On the variability of Gulf Stream transport from seasonal to decadal timescales. J. Mar. Res., 68, 503-522, https://doi.org/10.1357/002224010794657128.

Sanchez-Franks, A., and R. Zhang, 2015: Impact of the Atlantic meridional overturning circulation on the decadal variability of the Gulf Stream path and regional chlorophyll and nutrient concentrations. Geophys. Res. Lett., 42, 9889-9897, https://doi.org/10.1002/2015GL066262.

— S. Hameed, and R. E. Wilson, 2016: The Icelandic low as a predictor of the Gulf Stream North Wall position. J. Phys. Oceanogr., 46, 817-826, https://doi.org/10.1175/JPO-D-14-0244.1.

Sanders, F., 1986: Explosive cyclogenesis in the west-central North Atlantic Ocean, 1981-84. Part I: Composite structure and mean behavior. Mon. Wea. Rev., 114, 1781-1794, https://doi.org/ 10.1175/1520-0493(1986)114<1781:ECITWC >2.0.CO;2. 
Sasaki, Y. N., and N. Schneider, 2011: Interannual to decadal Gulf Stream variability in an eddy-resolving ocean model. Ocean Modell., 39, 209-219, https://doi.org/10.1016/j.ocemod.2011.04.004.

Taylor, A. H., 1995: North-south shifts of the Gulf Stream and their climatic connection with the abundance of zooplankton in the UK and its surrounding seas. ICES J. Mar. Sci., 52, 711-721, https://doi.org/10.1016/1054-3139(95)80084-0.

2005: A model of variations in the North Atlantic Oscillation. Geophys. Res. Lett., 32, L24713, https://doi.org/10.1029/ 2005 GL023792.

, and J. A. Stephens, 1980: Latitudinal displacements of the Gulf Stream (1966 to 1977) and their relation to temperature and zooplankton abundance in the NE Atlantic. Oceanol. Acta, 3, 145-149.

$\longrightarrow$, and - 1998: The North Atlantic Oscillation and the latitude of the Gulf Stream. Tellus, 50A, 134-142, https://doi.org/ 10.3402/tellusa.v50i1.14517.

Vimont, D., 2015: Meridional mode website. University of WisconsinMadison, accessed 6 June 2017, http://www.aos.wisc.edu/ dvimont/ MModes/Home.html.

- , and J. P. Kossin, 2007: The Atlantic meridional mode and hurricane activity. Geophys. Res. Lett., 34, L07709, https:// doi.org/10.1029/2007GL029683.

Wang, W., B. T. Anderson, R. K. Kaufmann, and R. B. Myneni, 2004: The relation between the North Atlantic Oscillation and SSTs in the North Atlantic basin. J. Climate, 17, 4752-4759, https://doi.org/10.1175/JCLI-3186.1.
Watelet, S., J.-M. Beckers, and A. Barth, 2017: Reconstruction of the Gulf Stream from 1940 to the present and correlation with the North Atlantic Oscillation. J. Phys. Oceanogr., 47, 27412754, https://doi.org/10.1175/JPO-D-17-0064.1.

Whalen, C. B., L. D. Talley, and J. A. MacKinnon, 2012: Spatial and temporal variability of global ocean mixing inferred from Argo profiles. Geophys. Res. Lett., 39, L18612, https://doi.org/ 10.1029/2012GL053196.

Wolfe, C. L., P. Cessi, and B. D. Cornuelle, 2017: An intrinsic mode of interannual variability in the Indian Ocean. J. Phys. Oceanogr., 47, 701-719, https://doi.org/10.1175/JPO-D-16-0177.1.

Xu, H., T. J. Miller, S. Hameed, L. A. Alade, and J. A. Nye, 2018 Evaluating the utility of the Gulf Stream index for predicting recruitment of southern New England-mid Atlantic yellowtail flounder. Fish. Oceanogr., 27, 85-95, https://doi.org/10.1111/ fog. 12236 .

Zeng, X., and R. He, 2016: Gulf Stream variability and a triggering mechanism of its large meander in the South Atlantic Bight. J. Geophys. Res. Oceans, 121, 8021-8038, https://doi.org/ 10.1002/2016JC012077.

Zhang, R., 2008: Coherent surface-subsurface fingerprint of the Atlantic meridional overturning circulation. Geophys. Res. Lett., 35, L20705, https://doi.org/10.1029/2008GL035463. , and G. K. Vallis, 2006: Impact of great salinity anomalies on the low-frequency variability of the North Atlantic climate. J. Climate, 19, 470-482, https://doi.org/10.1175/ JCLI3623.1. 